\title{
1 Application of Structure-from-Motion photogrammetry in laboratory flumes
}

\footnotetext{
*Corresponding author

Preprint submitted to Geomorphology

Email address: jacob.morgan@colostate.edu (Jacob A. Morgan) 
topographic data derived from SfM techniques; and (3) provide general guidance for image acquisition and processing for SfM applications in laboratory flumes. To investigate the effects of flume size, sediment size, and photo overlap on the density and accuracy of SfM data, we collected topographic data using both TLS and SfM in five flumes with widths ranging from 0.22 to $6.71 \mathrm{~m}$, lengths ranging from 9.14 to $30.48 \mathrm{~m}$, and median sediment sizes ranging from 0.2 to $31 \mathrm{~mm}$. Acquisition time, image overlap, point density, elevation data, and computed roughness parameters were compared to evaluate the performance of SfM against TLS. We also collected images of a pan of gravel where we varied the distance and angle between the camera and sediment in order to explore how photo acquisition affects the ability to capture grain-scale microtopographic features in SfM-derived point clouds.

A variety of image combinations and SfM software package settings were also investigated to determine optimal processing techniques. Results from this study suggest that SfM provides topographic data of similar accuracy to TLS, at higher resolution and lower cost. We found that about 100 pixels per grain are required to resolve grain-scale topography. We suggest protocols for image acquisition and SfM software settings to achieve best results when using SfM in laboratory settings. In general, convergent imagery, taken from 
39

40

41

42

43

44

45

46

47

48

49

57 et al., 2010).

Keywords:

a higher angle, with at least several overlapping images for each desired point in the flume will result in an acceptable point cloud.

Structure-from-Motion (SfM), terrestrial laser scanning (TLS), laboratory

flume methods, close-range photogrammetry, topographic modeling

\section{Introduction}

High-resolution topographic data collected during mobile-bed flume experiments has led to important advances in our scientific understanding of fundamental processes in river morphodynamics. For example, differencing successive topographic datasets can be used to quantify the formation and migration of alternate bars (Lisle et al., 1993; Lanzoni, 2000a,b; Venditti et al., 2012), the translation and dispersion of sediment pulses (Sklar et al., 2009; Humphries et al., 2012; Nelson et al., 2015), the formation and migration of meanders (Braudrick et al., 2009; van Dijk et al., 2012), and patterns of bedrock erosion (Johnson and Whipple, 2007; Finnegan et al., 2007). High-resolution topographic data can also provide important information about streambed structure (Aberle and Nikora, 2006), bed roughness, (Qin and Ng, 2012), and bed surface grain size (Butler et al., 2001; Nelson (et al. 2010 ). 
It generally is impractical to acquire dense topographic data manually using instruments such as point gages (Gilbert and Murphy, 1914; Brush and Wolman, 1960; Schumm and Khan, 1972). Thus, many modern flumes are outfitted with computer-controlled, mechanized instrumentation carts mounted with laser profilers (Marion et al., 2003; Aberle and Nikora, 2006; Nelson et al., 2009, 2010; Kim et al., 2015) and ultrasonic sensors (Kuhnle, 1993; Venditti et al., 2015). Cart-based measurement systems can be prohibitively expensive because such systems are generally highly customized and require high precision instrumentation to maintain accurate positioning during data collection. Terrestrial laser scanning (TLS), while primarily used in field-based applications (Brasington et al., 2012), has been used in some flume settings for comparative studies (Peter Heng et al., 2010; Smith and Vericat, 2014). TLS systems can, however, be extremely expensive and challenging to set up and use.

Digital photogrammetry provides an alternative to TLS or cart-based systems. Traditional close-range digital photogrammetry generally employs the use of multiple cameras to create 3D models of real space. These methods require either the precise location and angle of the camera position or the location of multiple ground control points in each image captured. Tra- 
77

ditional photogrammetry has been successfully used in both the field (e.g., Lane et al., 1993; Marzolff and Poesen, 2009) and laboratory (e.g., Chandler et al., 2001; Brasington and Smart, 2003; Stojic et al., 1998; Lane et al., 2001; Bertin et al., 2015). However, the use of these techniques appears to be limited due to the time required to set up such a system and the degree of expertise necessary for accurate reconstruction of a 3D surface (Smith et al., 2015).

An emerging photogrammetric technique that is gaining momentum in the geosciences is Structure-from-Motion (SfM). The concept behind SfM was introduced in the late 1970s (Ullman, 1979), but has risen to popularity among non-photogrammetrists following the work of Snavely et al. (2006). Structure-from-Motion uses multi-view computer vision methods that detect and match features between images to estimate the three-dimensional structure and camera locations and angles simultaneously (Lowe, 2004). There are a number of free software options for SfM processing (e.g., Bundler (Snavely et al., 2006), VisualSFM (Wu et al., 2011; Wu, 2013), and Autodesk ReMake (Autodesk, 2016)) as well as proprietary software (e.g., Arc3D (Tingdahl and Van Gool, 2011) and Agisoft PhotoScan (Agisoft, 2016a)). Compared with other close-range remote sensing techniques such as TLS and more tra- 
ditional photogrammetry, SfM is relatively low-cost and straightforward to process.

SfM techniques have already been used and tested in a wide array of field applications (e.g., Westoby et al., 2012; Fonstad et al., 2013; Micheletti et al., 2015), but few studies have used SfM in a laboratory setting (Marra et al., 2014; Kasprak et al., 2015; Ramos et al., 2015; Wang et al., 2016). This technology is becoming increasingly popular, but to our knowledge there have been no studies explicitly evaluating the relative performance of SfM against other methods of topographic measurement in a laboratory flume environment (but see Nouwakpo et al. (2014)), and there is a general lack of guidelines for SfM application in flume settings. This is especially problematic because experiments may be conducted in flumes spanning a wide range of physical scales (i.e., widths ranging from a few centimeters to several meters) using sediment ranging from silts or fine sands to large cobbles, and it is not clear how SfM data collection protocols and processing methods should change with flume scale, experimental grain size, or level of detail desired. These issues are all of great interest to experimentalists and therefore the objectives of this study were to: (1) compare the resolution and accuracy of SfM topographic measurements to TLS measurements in laboratory 
flume experiments of varying scale and grain sizes; (2) explore the effects of different image acquisition protocols and data processing methods on the resolution and accuracy of topographic data derived from SfM techniques; and (3) provide general guidance for image acquisition and processing for SfM applications in laboratory flumes.

\section{Methods}

For this study, we took advantage of several ongoing flume experiments being conducted at Colorado State University's Engineering Research Center. The flumes used in these experiments have widths varying from $0.22 \mathrm{~m}$ to $6.71 \mathrm{~m}$ and lengths from $9.14 \mathrm{~m}$ to $30.48 \mathrm{~m}$, and the sediment used in the experiments has median grain sizes ranging from $0.20 \mathrm{~mm}$ to $31 \mathrm{~mm}$. For each flume, we collected topographic data with two TLS systems, as well as a series of photographs taken at multiple locations with different camera angles that were later used to generate topographic data with SfM. This allowed us to quantitatively compare 3D point clouds generated from each method, and we can explore how the different image acquisition techniques affect topographic data for different flume scales and grain sizes, as well as how SfM processing techniques affect point cloud characteristics. Additionally 
images were acquired for sediment in a circular pan from a variety of distances and camera angles, for which a qualitative analysis allowed us to assess the requirements necessary to acquire grain-scale topography.

\subsection{Flume descriptions}

We collected data in five flumes (summarized in Table 1 and shown in Figs. 1a-e), which for this study we refer to with numbers 1 to 5 , where the smallest channel is Flume 1 and the largest is Flume 5. We also collected imagery for a pan filled with gravel (Fig. 1f). The grain size distributions of the sediment mixture in each flume and the pan are shown in Fig. 2.

Flume 1 is a narrow (0.22 m wide), $9.14 \mathrm{~m}$ long, rectangular channel that is deeper than it is wide (depth $=0.38 \mathrm{~m}$ ), with a sediment $D_{50}$ of $1.5 \mathrm{~mm}$. This flume has sinusoidal width variations in the downstream direction, and was used in the experiments described in Nelson et al. (2015). At the time of this study, the sediment bed in this flume exhibited riffle-pool topography, with locally high bed elevations in wide sections of the channel (riffles) and locally low elevations in narrow sections (pools).

Flume 2 is $1.22 \mathrm{~m}$ wide and $9.14 \mathrm{~m}$ long. It was being used to study processes in steep, coarse-grained rivers, and therefore had the coarsest sediment of any of the flumes in this study with a $D_{50}$ of $31 \mathrm{~mm}$. 
Flume 3 is $1.22 \mathrm{~m}$ wide and $18.29 \mathrm{~m}$ long, with a surface sediment $D_{50}$ of $4.1 \mathrm{~mm}$. This flume was being used to investigate alternate bar dynamics, and at the time of data acquisition this flume had approximately 1.5 alternate bar sequences and noticeable bed surface sorting (e.g., Nelson et al., 2010).

Flume 4 is a wide rectangular basin ( $4.88 \mathrm{~m}$ wide by $15.24 \mathrm{~m}$ long) that was being used to study flow and erosion around navigation locks. The sediment in this flume was a relatively well sorted (geometric standard deviation $\left.\sigma_{g}=1.67\right)$ gravel $\left(D_{50}=6.2 \mathrm{~mm}\right)$

Flume 5 is a large rectangular basin $(6.71 \mathrm{~m}$ wide by $30.48 \mathrm{~m}$ long $)$ filled with very well sorted $\left(\sigma_{g}=1.37\right)$ sand with $D_{50}=0.2 \mathrm{~mm}$. This basin was being used to perform experiments on braided channels in high sediment supply environments (Ettema et al., 2016), and at the time of data acquisition for this study the bed exhibited many shallow ( $\sim 1 \mathrm{~cm}$ depth) braided channels.

The pan is a circular container ( $0.39 \mathrm{~m}$ diameter) filled with a bi-modal mixture of very fine to coarse gravel. This container was not being used for any other experimentation and is only used in this study to examine the effect of camera distance/angle from the sediment surface. No TLS data were collected for the pan because the level of detail of interest is finer than the 
171

172

173

174

175

accuracy of TLS equipment available to us.

\subsection{Data acquisition}

\subsection{1. $T L S$}

Two TLS systems were used to collect topographic data. The first was a Leica ScanStation HDS3000, which is a time-of-flight style scanner with a stated accuracy of $\pm 6 \mathrm{~mm}$ at a distance of $50 \mathrm{~m}$ (Leica, 2016). This scanner computes distances using the speed of light by measuring the time from short pulses of light sent from the scanner until a reflection of the pulse is monitored (Paschotta, 2008). The second scanner was a Faro Focus3D S 120, which is a phase-shift scanner with a stated accuracy of $\pm 2 \mathrm{~mm}$ at a distance of $25 \mathrm{~m}$ (Faro, 2011). This scanner sends light with a known sinusoidal power modulation and measures distances by comparing this modulation with the phase of the power modulation that is reflected back to the scanner (Paschotta, 2008). In both cases, scanner accuracy should be better at closer ranges, to a point, since the range of accuracy cannot be any smaller than the laser point itself. Each flume was scanned by both scanners from three separate stations, one at the upstream end, one at the downstream end and one near the middle of the flume. Each scan contained a minimum of five reflective spheres that were used to align and position the three scans for 
a single flume. For two flumes the TLS stations were located with the instrument tripod on a cart that moves above the flume bed, and for the others the stations were located with the tripod at the bed level of the flume. The distance from the instrument to the flume bed depended on the dimensions of the flume and whether the station was on the flume cart or at the bed level. Scanner height above the bed varied from approximately 1.5 to $4 \mathrm{~m}$, resulting in overall distances generally less than those given for the stated accuracy by the manufacturers. The maximum downward angle of view for each of the scanners is $45^{\circ}$ and $27.5^{\circ}$, resulting in ranges from the scanner to the closest scanned points of 2.1 to $5.7 \mathrm{~m}$ for the Leica and 1.7 to 4.5 $\mathrm{m}$ for the the Faro. Point density using any TLS is highly dependent on the parameters defined by the user at the time of acquisition as well as the number of stations; here, we set the resolution of the TLS data acquisition so that measurements had a vertical and horizontal spacing of approximately 1 $\mathrm{cm}$ at a distance of $10 \mathrm{~m}$ from the instrument. Both Leica ScanStation and Faro Focus3D data were processed using the manufacturer's software, Leica Geosystems Cyclone and Faro SCENE, respectively. 


\subsubsection{Photographs for SfM}

Images were acquired using a Canon EOS Rebel T3i camera with a Canon EF-S $24 \mathrm{~mm}$ prime lens. This is a consumer grade DSLR camera capable of capturing images with 18.0 megapixel resolution. We acquired all images in both RAW and JPG formats (RAW file sizes are generally 3-4 times larger than their JPG counterparts), and we performed SfM processing with both file types to investigate the effects of digital image compression. The spacing of photograph locations and the angle of each photograph depended on the dimensions of the flume (Fig. 3a). First, a set of photographs was taken along the flume centerline. These camera positions were at an oblique angle ( $\sim 45^{\circ}$ below horizontal) positioned toward the flume bed pointing in both the upstream and downstream direction. These locations were evenly spaced along the longitudinal axis of the flume. The spacing was determined by the camera height above the bed relative to the flume width (e.g., Flume 1 is very deep relative to its width and therefore had finer spacing than some of the larger flumes (Table 2)). Photographs were also taken from the left and right edges of each flume, and these camera positions were also oriented at a vertically oblique angle $\left(\sim 45^{\circ}\right)$ looking down toward the flume bed. For the larger flumes (Flumes 4 and 5) camera azimuth angles were set to $0^{\circ}$ (di- 
rectly upstream), $45^{\circ}, 90^{\circ}$ (directly across the flume), $135^{\circ}$, and $180^{\circ}$ (directly downstream). For the smaller flumes (Flumes 1, 2, and 3) the side camera angles included $45^{\circ}, 90^{\circ}$ (directly across the flume), and $135^{\circ}$. These camera positions were uniformly spaced along the longitudinal axis at approximately the same locations as were collected for the upstream/downstream images. The most common parameterization used to characterize the overlap of images in a series or between lines is the percent overlap, particularly for aerial imagery. However, because of the multiple camera angles used in this study the overlap percentage between images is highly variable and difficult to interpret. We therefore used the of number of images in which any point is present as a metric to describe the image overlap. This number of overlapping images can easily be quantified spatially, as opposed to the percentage overlap. For aerial imagery Agisoft (2016b) suggests $80 \%$ forward overlap of images in a single flight line and $60 \%$ side overlap for adjacent flight lines. This corresponds to a maximum of 15 overlapping images when the camera orientation for all images is straight down. In our study, many locations were captured by more than 15 overlapping images because we took photographs from oblique angles.

Different combinations of the entire set of photographs were employed on 
Flumes 3 and 5 to test the effect of image orientation, number of images, and image overlap on SfM point cloud density and quality. The combinations included all images (All images) for both JPG and RAW, only images taken from the middle positions looking upstream and downstream (US-DS images), only images taken from the side of the flume (LB-RB images), only diagonal images taken from the side of the flume (LB-RB angled images; i.e., $45^{\circ}$ and $135^{\circ}$ images only), only images taken from the middle of the flume with $45^{\circ}$ and $135^{\circ}$ images from the side of the flume (no cross-flume images), all images from every second position, all images from every third position, and all images from every fourth position (Fig. 3b).

Photographs for the pan were collected using the same camera and lens as for the flumes. The pan filled with sediment was placed on a rotating turntable and the camera was positioned at six different distances (approximately $0.5,0.75,1,1.5,2$, and $3 \mathrm{~m}$ ) from the center of the pan to the camera sensor for two angles $\left(30^{\circ}\right.$ and $\left.60^{\circ}\right)$ above horizontal (Fig. 3c). Images of the turntable were taken at $10^{\circ}$ intervals, resulting in 36 images for each distance at each camera angle (Fig. 3d). Seven markers were placed on the turntable around the pan to aid in both image alignment and point cloud scaling/referencing. 


\subsection{SfM point cloud creation}

Three-dimensional point clouds were created from each set of images using two different SfM software options: Agisoft PhotoScan Professional version 1.2.3 (Agisoft, 2016a) and VisualSFM version 0.5 (Wu et al., 2011; Wu, 2013). Photoscan is widely used proprietary software that allows the user to select the level of alignment accuracy and dense cloud quality. VisualSFM (VSFM) is freely available from http://ccwu.me/vsfm/ and implements a scale invariant feature transform (SIFT) (Lowe, 2004) and mutli-core bundle adjustment (Wu et al., 2011) to recreate a three-dimensional scene from the two-dimensional images $(\mathrm{Wu}, 2013)$. The software also has the ability to integrate the Clustering Views for Multi-view Stereo/Patch-based Multi-view Stereo version 2 (CMVS/PMVS2) tool developed by Furukawa and Ponce (2010) to create a denser point cloud.

Comparisons between SfM and TLS elevation datasets used SfM point clouds generated from all of the images acquired in each flume. The SfM datasets generated in PhotoScan used a photographic alignment accuracy set to "highest" (out of the options "lowest", "low", "medium", "high", and "highest") and a dense cloud quality set to "medium" (out of the options "lowest", "low", "medium", "high", and "ultra high"). Although PhotoScan 
has the ability to specify targets or ground control points to aid in image matching, no targets were specified for the objective of testing these different settings. Although some process settings can be specified by the user in VSFM, only default settings were used for this study.

In order to explore the effect of the user-controlled settings in PhotoScan on the final point cloud density and quality, we processed the photos taken of Flume 3 in a variety of ways and compared the results. We varied the alignment accuracy setting from "lowest" to "medium" to "highest" and we varied the dense cloud quality setting from "lowest" to "medium" to "ultra high". Additionally, we tested the effect of selecting targets in the software processing for three of the image combinations: all images, US-DS images, and LB-RB images. Printable targets were obtained through PhotoScan software. For Flumes 2 and 3 targets had previously been taped to the inside of the flume walls at a spacing of approximately $0.5 \mathrm{~m}$ in the downstream direction. For Flumes 1, 4, and 5, targets were spread out at the edges of the imaged area, either in or around the flumes.

Point clouds for the pan experiment were generated in PhotoScan using the "highest" alignment accuracy setting and the "ultra high" dense cloud quality setting. 


\subsection{Point cloud scaling and alignment}

The free, open-source software CloudCompare (Girardeau-Montaut, 2011) was used to align and scale the SfM point clouds, and to align the Faro point clouds to the Leica point clouds. This process began by importing all the clouds for a given flume. Three readily identifiable points in common between each cloud (e.g., flume wall corners) were selected to initially align the reference cloud to the Leica base cloud. These point clouds were all clipped to a rectangular box that eliminated points outside the flume, yet kept the walls. The iterative closest point (ICP, see Besl and McKay, 1992) algorithm was then used to finely register the two point clouds together by using a random sampling limit of 100,000 points and was reduced to a root mean square (RMS) difference between the point clouds of $1.0 \times 10^{-5} \mathrm{~m}$. The point clouds were then clipped such that walls and structures in the flume were removed. The pan point clouds were aligned using measured arbitrary coordinates in the scene. Seven markers were placed around the pan and the coordinates of each of those targets were used in all the photosets to scale and align each point cloud in PhotoScan. The point clouds were clipped to a circular area such that the rotating turntable and pan edges were removed. 


\subsection{Point cloud processing}

In order to quantitatively compare the TLS and SfM methods, point cloud post-processing consisted of calculating statistics related to model elevations, two surface roughness metrics, and computation of the spatial differences between each point cloud. The first surface roughness calculation was a single value for rugosity, which was measured for the entire final, clipped point cloud for each flume. Rugosity is defined as the 3D surface area of a region divided by the planimetric, or $2 \mathrm{D}$, surface area of the same region (Brasington et al., 2012). A triangulated irregular network (TIN) was created from each point cloud in ArcGIS and the 'Surface Volume' function in the 3D Analyst toolbox calculated the necessary areas. The second approach of estimating surface roughness was to use a spatially variable roughness index-elevation. This measure of roughness is computed as the standard deviation of residual topography across a moving window for a specified number of cells (e.g., Cavalli et al., 2008; Prosdocimi et al., 2015). For this calculation the point cloud data were first gridded onto a raster with $1 \mathrm{~cm}$ cells. Residual elevations were computed by differencing each cell's value in a $5 \times 5$ cell window with the mean value of those same 25 cells. The roughness index-elevation of the cell in the center of the window is defined as 
the standard deviation of those elevation residuals (see Cavalli et al., 2008, for more details). Ideally both the raster cell size and computation window size would vary according to point density, grain size, feature size, and noise (Prosdocimi et al., 2015). However, because we are mainly interested in the differences between methods, we used the same cell and window size for all five flumes and all four methods of point cloud creation. Roughness values may not be comparable between flumes because the number of grains present in the $5 \times 5$ cell window will depend on the grain-size distribution of the sediment in each flume.

Point cloud differencing was computed using the Multiscale Model to Model Cloud Comparison (M3C2) algorithm (Lague et al., 2013). This differencing method is available in CloudCompare and requires the user to define several parameters. The general concept behind $\mathrm{M} 3 \mathrm{C} 2$ is to compute cloud-to-cloud distances using a local normal direction rather than only the vertical direction. The normal direction is computed from the points within a sphere around a given point, defined by the so-called "normals diameter". Once the normal direction is computed, the algorithm creates a cylinder oriented along the normal vector, with a diameter (the "projection diameter") specified by the user. The intersection of each point cloud with this cylinder 
defines two subsets, which are projected on to the axes of the cylinder and used to compute a distribution of normal distances between the two clouds at that location. More details on the $\mathrm{M} 3 \mathrm{C} 2$ algorithm are provided by Lague et al. (2013).

For the purpose of our study we chose to always specify the point cloud with fewer points as the reference cloud, and also chose to use the entire reference point cloud to be the core points for which $\mathrm{M} 3 \mathrm{C} 2$ differences were computed. A sensitivity analysis on the mean, median and standard deviation of the $\mathrm{M} 3 \mathrm{C} 2$ differences for Flume 3 were relatively insensitive to adjusting the normal and projection diameters. We ultimately chose to use normal and projection diameters of $5 \mathrm{~cm}$ and $1 \mathrm{~cm}$, respectively, for all of the flumes. Lague et al. (2013) suggest that these values should vary relative to local point cloud roughness, however for simplicity and consistency we elected to use the same values for all flumes and point clouds. Unlike many previous SfM validation studies which compared SfM models to other models by first converting one or both point clouds to rasters (Smith et al., 2015), the $\mathrm{M} 3 \mathrm{C} 2$ algorithm allowed us to compare point clouds directly. $\mathrm{M} 3 \mathrm{C} 2$ differences were computed for all point cloud combinations.

Considering the accuracy of the TLS units and the fine level of detail in 
377

the imagery and subsequent SfM point clouds for the sediment in the pan experiment, no TLS data were collected. Instead, the different SfM point clouds were qualitatively evaluated against one another to determine whether individual grains were discernible and at what distance the differences between individual grains was smoothed over.

\section{Results}

\subsection{TLS and SfM comparisons}

\subsubsection{Point density and image overlap}

The horizontal spacing between photographs was varied between flumes due to their varied sizes (Table 2), which resulted in substantial photo overlap across most of the flume for all flumes (Figs. 4a-8a). Larger flumes contain areas with greatest image overlap and the greatest overlap generally occurs near the center of the flume just downstream from the middle. For each flume the point count and point density vary over an order of magnitude (Table 2). In every case the Leica model contains the fewest number of points. The TLS models nearly always have lower point counts than the SfM models, with the exception of Flume 5, where the Faro model contains more points than the VSFM model. Spatial distributions of the point density results for 
the TLS models in each flume illustrate a strong dependency on the location of the TLS scanner (Figs. 4b-8b), where overlapping scans had one or more orders of magnitude more points than areas that were only included in a single scan. The point density map of the VSFM model of Flume 5 shows large gaps where no point data exists (Fig. 8b).

\subsubsection{Bed elevations and roughness metrics}

Elevation values for each method are generally similar for each flume (Figs. 4c-8c); however, the range of elevation values for the VSFM model in Flume 4 is greater than the other clouds (Table 3). Both rugosity and the roughness index-elevation calculations were derived from elevation values (Table 3). Rugosity is greatest for Flume 2 where the $D_{50}$ is $31.0 \mathrm{~mm}$, and in Flume 4 the rugosity for the VSFM model is nearly four times that of the other models. The maps of the roughness for each flume illustrate both form and grain roughness features such as alternate bar edges in Flume 3 and individual grains in Flume 2 (Figs. 4d-8d). For each flume both rugosity and roughness index-elevation values are generally greatest for the VSFM models. 


\subsubsection{M3C2 differences}

Differences computed using the $\mathrm{M} 3 \mathrm{C} 2$ algorithm show that for most of the flumes $98 \%$ of the computed differences lie within $2 \mathrm{~cm}$ of each method (Fig. 9), with the exception of Flume 2 and some comparisons in Flume 5. Figs. S1 through S5 in the Supplemental Information show the spatial distribution of $\mathrm{M} 3 \mathrm{C} 2$ differences for all model comparisons. Root mean square (RMS) values for the $\mathrm{M} 3 \mathrm{C} 2$ differences are consistently at or under $1 \mathrm{~cm}$ for all flumes except Flume 2. Comparisons between the two TLS models generally have the smallest range of $\mathrm{M} 3 \mathrm{C} 2$ distance encompassing the middle $98 \%$, with the exception of Flume 2. Comparisons between all of the models in Flume 3 are the most consistent with RMS values varying between 2-3 mm.

\subsection{Image combinations}

The spatial patterns of image overlap for the different photo acquisition protocols for Flume 3 are shown in Fig. 10. The smallest number of overlapping images for any area is four, which occurs for the image combination including only angled images taken from the side (LB-RB angled images). The greatest number of overlapping images, 51, occurs when all images are used. Despite the different amount of overlap between image combinations, there was little difference in the number of points in each point cloud for 
Flume 3 (Table 4). The combination using only images taken from the middle of the flume pointing in the upstream and downstream directions (US-DS images) was not able to align in PhotoScan without the selection of targets. Alignment was unable to be performed, with or without targets specified, for image combinations using images acquired from every third and every fourth position. Computed M3C2 distances between each of the image combinations and select combinations with and without targets specified against the Leica model show relatively little difference (Fig. 11 and supplemental Fig. S6). Median and RMS values for these M3C2 differences show almost no variation between image combinations (Table 4).

Image overlap maps computed from different image combinations for Flume 5 are shown in Fig. 12. The maximum number of overlapping images for any point is 96 and occurs when all the images are used. The minimum is one, occurring for the LB-RB angled images. There is greater range in the point counts for different image combinations of Flume 5, with models created from RAW images, US-DS images, and every third position having about half the point count as the other image combinations (Table 5). Alignment was unable to be performed, with or without targets specified, for the image combination using images acquired from every fourth position. 
There is greater range in the $\mathrm{M} 3 \mathrm{C} 2$ distances from the Leica model for point clouds of Flume 5 than Flume 3 (Fig. 13). The spatial distribution of these M3C2 distances are shown in supplemental Fig. S7. Median values for RAW images and every third position and RMS values for RAW images, RB-LB angled images, and every third position are greater than the other image combinations.

Although PhotoScan has the option of automatically detecting targets in the input images, we have not had luck with that feature. The placement of targets required the manual selection of the markers in each image in PhotoScan. For each photoset this took approximately $30 \mathrm{~min}$.

\subsection{PhotoScan settings}

Calculated M3C2 distances between models of Flume 3 using the different qualitative settings for PhotoScan's processing of both image alignment accuracy and dense point cloud quality against the Leica model are summarized in Fig. 11, with the spatial distribution of these distances shown in supplemental Fig. S8. These results show a slight decrease in central $98 \%$ of $\mathrm{M} 3 \mathrm{C} 2$ distances as the accuracy and quality settings are increased. However, the median and RMS values for the M3C2 distances between the SfM clouds and the Leica TLS cloud show very little variation between Pho- 
toScan settings (Table 6). The primary differences between settings are in the point count for each model and the processing time, which for a typical desktop computer is roughly on the order of minutes for lowest quality, hours for medium quality and days for ultra high quality. The dense cloud quality setting has a much larger effect on point density than image alignment accuracy, where total point counts between dense cloud qualities of "Lowest", "Medium", and "Ultra High" vary by over an order of magnitude each (Table 6). Therefore, the "quality" setting in creating dense clouds is analogous to density.

\subsection{Camera distance and angle}

A summary of point counts for the point clouds generated in the pan experiment is shown in Table 7. The difference in point count is much more pronounced between the different distances than between the two different angles. There is a general power-law decay in model point count with increased distance between the camera and subject (exponent of approximately -2.15). Although the point clouds generated from $30^{\circ}$ imagery tended to have a higher point count than those generated from $60^{\circ}$ imagery the differences are minor. Figs. 14 and 15 show selected cross-section profiles of the created point clouds through the center of the circular pan (an animation showing 
cross-section profiles for every $1^{\circ}$ of rotation is available with the supplemental material). Both the clouds from $30^{\circ}$ images and $60^{\circ}$ images show a "smoothing" with increased distance between the camera and the surface. For the models made from the closest imagery the interstices between individual grains are relatively clear. As the camera distance increases the difference between the "lows" separating grains and the "highs" at grain apexes are reduced, especially for the smaller grains (e.g., those at the right of the plots in Fig. 15).

\section{Discussion}

\subsection{TLS and SfM Comparisons}

The image count for each flume is mostly a function of flume dimensions and the camera height above the flume bed. In general the maximum image overlap increases with increasing flume size. Flumes 2 and 5 each have a concentration of high image overlap slightly downstream from the middle of the flume, which can be explained by the slope of the flume bed, i.e., camera positions looking in the downstream direction are able to see a greater area of the flume bed because the bed is sloping away from the camera's viewpoint. Flume 3 also appears to have an area of high image overlap 
slightly downstream from the middle, however, it should be noted that the data shown in Fig. 7 are clipped and do not represent the total area of the flume. The suggestion of Agisoft (2016b) for $80 \%$ forward overlap of images in a single flight line and $60 \%$ side overlap for adjacent flight lines corresponds to a maximum image overlap count of 15 , generally well below what we achieved with our image overlap.

Processing time for both the TLS and SFM methods are highly dependent on the size of the dataset, computer power, and the user familiarity with the software. We did not include processing time for each method as we used multiple computers, each with different processors and available RAM. Raw data acquisition time was generally lower for the SfM imagery than the TLS scans, with the single exception of the Faro in Flume 5. To obtain data of similar point densities with manual measurements would take an extremely long time. Even more modern, conventional methods of measuring flume topography could potentially be very time consuming. Lane et al. (2001) reported an acquisition time of $8 \mathrm{~h}$ to obtain data necessary to create a DEM with $0.5 \mathrm{~mm}$ resolution on a $0.25 \mathrm{~m} \times 0.25 \mathrm{~m}$ area, using a laser sensor on a motorized cart. The SfM imagery for each of the smaller flumes was collected in less than an hour and produced point clouds with multiple points 
per $\mathrm{mm}^{2}$ (Table 2). By adjusting the software settings the point density has the potential to increase dramatically (Table 6). In the pan experiment imagery for each photoset required mere minutes to collect and resulted in a coverage area nearly twice that used by Lane et al. (2001) and at a minimum of several points per $\mathrm{mm}^{2}$.

The point counts and spatial point densities of the topographic models show a high dependence on the method used to collect the data. The lower point count and density associated with the TLS models is due largely to both the limited number of scanning positions and the settings of each scanner. Had more scans been performed from additional stations or scanner resolution increased the point counts would have been higher, but at the cost of additional acquisition and processing time. Lower point density in areas of less image overlap would seem logical, however it came as a surprise that PhotoScan models show a spatially consistent point density for each flume. The VSFM models, on the other hand, show spatial point density distributions with generally lower values near the flume walls. The average point densities between the two SfM models are comparable to one another with the exception of Flume 5, where PhotoScan produces a model with twice the density of VSFM. Based on the spatial distribution of points in the VSFM 
model we suspect that the software had a difficult time with the apparent lack of texture and color of the fine sand surface. PhotoScan, however, continued to produce a spatially consistent point cloud, even in areas with little texture. Given the proprietary nature of the algorithms in PhotoScan, it is difficult to know for certain the reason it produces more consistent point densities.

In general the elevation values and ranges for the different methods are comparable to one another. The VSFM model for Flume 4, however, has an elevation range two to three times larger than the other models (Table 2). This high elevation variability is obvious in the elevation map and propagates to produce higher ranges in roughness (Fig. 7). With the similarity in grain sizes between Flumes 3 and 4, this wider range of elevations in the VSFM model for Flume 4 can likely be attributed to two factors. First, as a result of the greater flume width/height the camera positions for Flume 4 were located a greater distance from the bed than the camera positions for Flume 3. Smith and Vericat (2015) report from more than 15 validation studies that the root mean square error of SfM models increases linearly with the range of imagery from the subject. However, the range scales reported there cover three orders of magnitude, which is much more variation than what 
we have between Flumes 3 and 4. Still, the closer camera angles for Flume 3 are more likely to produce more consistent feature matches of individual grains in the images, while single grain features may be difficult to match in Flume 4. Second, the wider range of elevations in the VSFM model of Flume 4 may be due to a relative lack of image texture. Flume 3 had both a wider range of grain sizes as well as grains of different colors, while the grains in Flume 4 were of more uniform size and color. This may have produced difficulty in feature detection and matching that was exacerbated by the dark color of the sediment and relatively low lighting. It is curious, however, that such elevation variability was produced in the VSFM model but not the PhotoScan model. Again, without knowledge of PhotoScan algorithms it is difficult to interpret the different results from the two SfM software packages. A lack of image texture also likely contributed to the elevation variability in the VSFM model of Flume 5 (Fig. 8).

Similar to the elevation results, rugosity and roughness index-elevation calculations are comparable for each model. Smaller grain sizes and topographic relief (e.g., Flume 5) result in much lower roughness parameters than larger grain sizes (e.g., Flume 2) and more significant relative topographic relief (e.g., Flume 1) (Table 3). As mentioned previously, the "noise" in some 
of the elevation values can propagate to create variability in the roughness metrics. It should be remembered that we used the same moving window and cell size for roughness index-elevation calculations regardless of grain size. For most of the flumes both elevation and roughness calculation are comparable between the TLS and SfM models despite large differences in point densities.

The M3C2 distances show a high degree of variability across flumes, and among models (Fig. 9). The widest range of M3C2 distances occurs for the models of Flume 2, and this is primarily due to "shadows" in the TLS models, resulting in limited coverage between grains. In contrast the SfM approaches were more capable of creating detailed topography between grains due to the hundreds more locations from which photos were taken, as compared to the three instrument points used in the TLS data acquisition. An additional source of discrepancy could stem from error in the computed normal directions in the $\mathrm{M} 3 \mathrm{C} 2$ algorithm, which would result in greater $\mathrm{M} 3 \mathrm{C} 2$ distances between point clouds. It has also been pointed out that rough surfaces result in increased error effects (Prosdocimi et al., 2015). Computed distances between models mostly fall within $\pm 2 \mathrm{~cm}$ for Flumes 1, 4 and 5, and more than $98 \%$ of the measured distances are within $\pm 1 \mathrm{~cm}$ for Flume 3. M3C2 
distances for Flume 2 reach upwards of $7 \mathrm{~cm}$ as a result of the higher roughness. In most cases the distances between the two TLS models is the lowest, and the distances between the TLS and SfM models fall within the reported error range of the TLS instruments.

The spatial distribution of $\mathrm{M} 3 \mathrm{C} 2$ distances does not appear to show any patterns except for in Flume 1 where there is obvious nonlinear longitudinal deformation in the SfM models (Fig. 16). Because of the deep and narrow dimensions of Flume 1 the differences in camera angles are minute and result in more-or-less parallel imagery. James and Robson (2012) note that SfM analyses generally rely on angles that are convergent rather than parallel, and parallel imagery in other close-range photogrammetry applications has been shown to result in lens model errors propagating and expounding in the 3D model to produce a "dome" effect (e.g., Wackrow and Chandler, 2008, 2011). Interestingly, the direction of deformation of the PhotoScan and VSFM models are reversed from one another, highlighting another apparent difference in algorithms. It should be noted, however, that the measured magnitude of the doming effect in the SfM Models for Flume 1 is approximate to the range of accurate measurements for the TLS machines (Leica, 2016; Faro, 2011). The other flumes had sufficient convergence of images to avoid 
noticeable nonlinear deformation, demonstrating the importance of including convergent imagery during acquisition.

\subsection{Image Combination and PhotoScan Setting Comparisons}

Understandably the number of overlapping images depends on both the number of camera positions and camera orientation (Figs. 10 and 12). The fact that the US-DS image combination for Flume 3 contains nearly the same number of images as the every third position combination (Table 4) yet has image overlap 4-6 times higher (Fig. 10) illustrates the importance of image orientation on achieving overlap. Similarly, the fact that the US-DS images were able to be aligned for Flume 3 while every third position could not be aligned further implies the importance of overlap rather than number of images alone. For Flume 3 the corresponding point counts for the models produced from different image combinations somewhat follow the image count, but the differences are minor. For Flume 5 the point counts do not seem to follow any pattern. The fact that upstream and downstream oriented images taken from a position in the center of flume can only be aligned if targets are used is likely due to the extreme angle $\left(180^{\circ}\right)$ between the two orientations. The measured $\mathrm{M} 3 \mathrm{C} 2$ differences of each image combination model against the Leica model for Flume 3 show very little deviation, suggesting that as 
long as PhotoScan is able to align images and create a 3D model the quality of point cloud is largely independent from both the number of images as well as the amount of image overlap (Fig. 11). We did not find any significant difference in using RAW imagery versus JPG files. However, in cases of overor under-exposure and high lighting contrast, RAW images may have an advantage because their ability to retain more detailed color depth. Similarly, the selection of targets did not result in a significant change in $\mathrm{M} 3 \mathrm{C} 2$ distances, however, the selection of targets is sometimes necessary for camera alignment to be successful, as seen in the case of the US-DS images. Target identification also provides a convenient method for scaling and aligning a point cloud, as would be necessary for a field application.

The primary difference between the variations in PhotoScan settings is the processing time required and the point count of the consequent model (Table 6), and even then only for the setting of dense construction quality. While the lowest alignment accuracy setting and the lowest dense quality setting produce a wider central $98 \%$ of $\mathrm{M} 3 \mathrm{C} 2$ differences, it is still only on the order of millimeters and within the range of variability of the measurements themselves (Fig. 11). However, the model created using the lowest accuracy alignment shows a range of $\mathrm{M} 3 \mathrm{C} 2$ differences 5-6 $\mathrm{cm}$ greater than the models 
created using other PhotoScan settings. Considering this, the selection of PhotoScan settings should be guided by particular applications and point cloud uses. For example, a dense quality set to "lowest" should probably only be used for qualitative assessment.

\subsection{Camera Distances and Angles}

In the results from our pan experiment, the differences are minute between the point clouds produced using SfM from images taken at different angles below horizontal and different distances between the camera and sediment surface (Figs. 14 and 15). In general the elevation differences in the cross-section profiles are no more than a millimeter or so. The major exception is in the interstices between some of the grains, where the closer camera locations show lower elevations (i.e., more pronounced differences between grains). In most cases the 0.5 and $0.75 \mathrm{~m}$ distance clouds fall very closely to one another, capturing the interstices between the fine particles, and the 2 and $3 \mathrm{~m}$ clouds fall closely to one another, smoothing over the interstices between the fine particles. Due to the higher angle and consequent ability to capture deep interstitial space between grains the $60^{\circ}$ imagery seems to capture this void more readily and at greater distances than the $30^{\circ} \mathrm{im}-$ agery. The $1 \mathrm{~m}$ imagery represents an apparent transition between photo 
sets whose point clouds resolve the spaces between $2 \mathrm{~mm}$ particles and those that smooth over fine grain-scale detail. The Canon EOS Rebel T3i that was used to capture imagery has a megapixel (MP) count of 18 and with the 24 mm lens each image has approximately 2400 pixels across the pan diameter $(0.385 \mathrm{~m})$, resulting in a pixel spacing of equivalent to 6 pixels $/ \mathrm{mm}$ with the camera located $1 \mathrm{~m}$ from the center of the pan. Because the imagery was taken from an oblique angle finer pixel spacing occurs closer to the camera (and conversely, coarser spacing farther). An unobstructed $2 \mathrm{~mm}$ grain (the smallest in the pan and assumed to be completely visible as a circle) would then occupy about 113 pixels (assuming the cross-sectional area of the grain is about $\left.3.14 \mathrm{~mm}^{2}\right)$, given the 6 pixels $/ \mathrm{mm}\left(36\right.$ pixels $\left./ \mathrm{mm}^{2}\right)$ resolution at $1 \mathrm{~m}$ camera distance. From a camera distance of $1.5 \mathrm{~m}$ the average approximate pixels to $2 \mathrm{~mm}$ grain ratio decreases to 49 . These findings suggest that SfM may be used to capture grain scale topography for particles occupying about 100 pixels, so the camera sensor resolution, lens focal length, and smallest resolvable grain-scale desired can be used to determine the distance.

\subsection{Guidelines \& Recommendations for SfM in Flumes}

Our results suggest that SfM can produce topographic point clouds in flumes with quality comparable to TLS and much greater point density, with 
less acquisition time and at much lower overall cost. However, SfM may not perform as optimally for deep and narrow flumes, such as Flume 1, where it is difficult to obtain images from sufficiently convergent angles to completely alleviate lens distortion issues. Also, SfM requires image texture to define features and in cases of very small grains with camera positions a significant distance from the flume bed, as in Flume 5, some SfM algorithms may have difficulty in defining and matching features. Sediment of nearly all the same size and color under low light, as in the case of Flume 4, can also produce poor feature detection and matching. In these cases we would recommend additional ground control points on the flume surface and/or supplementary light sources to potentially increase image texture. However, care should be taken to ensure light sources are outside the field of view of the imagery and the camera flash should not be used (Agisoft, 2016b).

For image acquisition, we simply recommend that images are taken at a number of positions and angles that provide sufficient coverage of the flume bed. Agisoft's (2016b) recommendations of overlap of $80 \%$ in the downstream and $60 \%$ in the cross-stream directions result in an image overlap count of 15 and this seems like a reasonable goal. Insufficient overlap, which seemed to be the case when we skipped every third or fourth position in Flume 3, 
can make photo alignment impossible or significantly reduce the quality of the resultant model. If the differences between camera angles are too great it may be necessary to specify targets for the camera alignment. In our image combinations for both Flumes 3 and 5 the upstream and downstream facing camera angles from the center of the flume provided an acceptable output model with the fewest number of images. In general we found no significant difference in RAW imagery verses JPG, but for situations of under- or overexposure we expect that RAW images may produce more satisfactory results. PhotoScan consistently produced more satisfactory results than VisualSFM, particularly for point density. When selecting PhotoScan settings we recommend the default settings in version 1.2.3.2016 with the photo alignment accuracy set to "highest" and the dense cloud quality set to "medium". For cases where very high point density is required it may be necessary to increase the dense cloud quality, however it should be noted this significantly increases the processing time.

The camera distance from the subject will depend greatly on the detail required as well as the sensor resolution and focal length. If sub-grain scale topography is required, we suggest positioning the camera a distance from the flume bed such that 100 pixels per grain is achieved. In our experiment 
the imagery captured from a steeper angle above the horizontal seemed to result in a point cloud that characterized the interstices between grains more clearly, especially at farther distances. However, for cases of very poorly sorted sediment, for which there is little to no interstitial space, the angle of the camera would likely have less of an effect.

\section{Conclusions}

The lack of previous work involving Structure-from-Motion photogrammetry methodology in laboratory flumes has led us to conduct a series of experiments to explore how flume size, sediment size, photo acquisition, and software processing affects the density and accuracy point clouds derived using SfM photogrammetry. TLS and photographs were collected for five laboratory flumes, for which the resulting topographic models were compared, and photographs were collected at varying angles and distances from a pan of sediment to assess the ability to accurately characterize grain scale topography.

Both PhotoScan and VisualSFM tended to have comparable elevation accuracy, but PhotoScan generally produced more uniformly high point density than VisualSFM, and VisualSFM produced noisier topographic data for 
flumes of large size, low relief, and uniform grain size. Comparisons between different combinations of images show that the number of images, camera orientation, and number of overlapping images have little bearing on the character of the resultant point cloud model, either in total point count or in $\mathrm{M} 3 \mathrm{C} 2$ distance from the Leica TLS model. Process settings in the PhotoScan software also showed to have negligible effect on the distance from the Leica TLS model. However, the dense quality setting did have a significant effect on the total point count in the resultant model and the processing time. The pan experiment showed that fine-scale detail decreased with increased distance between the camera and the subject. Point count was shown to decrease with distance as a power function to the -2.15 . Imagery taken at a steeper angle also produced more defined boundaries between grains. We suggest that the finest grain-scale topography likely to be resolvable using SfM photogrammetry methods will correspond to grains occupying about 100 pixels in the digital imagery.

These results ultimately indicate that SfM photogrammetry provides a viable alternative to other topographic measurement techniques, with the ability to provide higher resolution datasets of comparable quality, at a fraction of the cost and time. Additionally, the SfM photogrammetry software 
771 proved to be more intuitive and present less of a learning curve than TLS 772 processing software. Given these considerations we expect SfM photogram773 metry to continue gaining popularity in flume experiments, as well as other 774 physical sciences.

\section{Acknowledgements}

776 We would like to acknowledge Andy Bankert and Dr. Lina Polvi for 777 providing grain size distributions for Flumes 2 and 3, respectively. We also

\section{Appendix A. Supplementary Data}

Supplementary data associated with this article can be found in the online version, at doi: 


\section{References}

Aberle, J., Nikora, V., 2006. Statistical properties of armored gravel bed surfaces. Water Resources Research 42. doi:10.1029/2005WR004674.

Agisoft, 2016a. Agisoft PhotoScan Professional Edition, version 1.2.3.2016. URL: http://www.agisoft.ru/products/photoscan/. accessed 30 January 2016.

Agisoft, 2016b. Agisoft PhotoScan User Manual, Professional Edition, version 1.2. URL: http://www.agisoft.com/pdf/photoscan-pro_1_2_en.pdf. accessed 30 January 2016.

Autodesk, 2016. Autodesk ReMake: High Definition 3D from Reality. URL: https://remake. autodesk. com/about. accessed 19 September 2016.

Bertin, S., Friedrich, H., Delmas, P., Chan, E., Gimelfarb, G., 2015. Digital stereo photogrammetry for grain-scale monitoring of fluvial surfaces: Error evaluation and workflow optimisation. ISPRS Journal of Photogrammetry and Remote Sensing 101, 193-208. doi:10.1016/j.isprsjprs.2014.12.019.

Besl, P.J., McKay, N.D., 1992. Method for registration of 3-d shapes, in: 
Robotics-DL tentative, International Society for Optics and Photonics. pp. 586-606. doi:10.1117/12.57955.

Brasington, J., Smart, R., 2003. Close range digital photogrammetric analysis of experimental drainage basin evolution. Earth Surface Processes and Landforms 28, 231-247. doi:10.1002/esp.480.

Brasington, J., Vericat, D., Rychkov, I., 2012. Modeling river bed morphology, roughness, and surface sedimentology using high resolution terrestrial laser scanning. Water Resources Research 48. doi:10.1029/2012WR012223.

Braudrick, C.A., Dietrich, W.E., Leverich, G.T., Sklar, L.S., 2009. Experimental evidence for the conditions necessary to sustain meandering in coarse-bedded rivers. Proceedings of the National Academy of Sciences of the United States of America 106, 16936-16941. doi:10.1073/pnas.0909417106.

Brush, L.M., Wolman, M.G., 1960. Knickpoint behavior in noncohesive material: a laboratory study. Geological Society of America Bulletin 71, 59-74. doi:10.1130/0016-7606(1960)71[59:KBINMA]2.0.CO;2.

Butler, J.B., Lane, S.N., Chandler, J.H., 2001. Automated extraction of 
grain-size data from gravel surfaces using digital image processing. Journal of Hydraulic Research 39, 1-11. doi:10.1080/00221686.2001.9628276.

Cavalli, M., Tarolli, P., Marchi, L., Dalla Fontana, G., 2008. The effectiveness of airborne lidar data in the recognition of channel-bed morphology. Catena 73, 249-260. doi:10.1016/j.catena.2007.11.001.

Chandler, J.H., Shiono, K., Rameshwaren, P., Lane, S.N., 2001. Measuring flume surfaces for hydraulics research using a Kodak DCS460. The Photogrammetric Record 17, 39-61. doi:10.1111/0031-868X.00167.

van Dijk, W.M..M., van de Lageweg, W.I..I., Kleinhans, M.G..G., 2012. Experimental meandering river with chute cutoffs. Journal of Geophysical Research 117. doi:10.1029/2011JF002314.

Ettema, R., Armstrong, D.R., Thornton, C.I., Hughes, S.A., Abt, S.R., 2016. Hydraulic modeling of braided channels self-formed in an alluvial plain, in: Constantinescu, G., Garcia, M., Hanes, D. (Eds.), River Flow 2016, CRC Press-Taylor \& Francis Group. pp. 1106-1112.

Faro, 2011. Faro Laser Scanner Focus3D. Technical Sheet.

Finnegan, N.J., Sklar, L.S., Fuller, T.K., 2007. Interplay of sediment supply, 
river incision, and channel morphology revealed by the transient evolution of an experimental bedrock channel. Journal of Geophysical Research 112. doi:10.1029/2006JF000569.

Fonstad, M.A., Dietrich, J.T., Courville, B.C., Jensen, J.L., Carbonneau, P.E., 2013. Topographic structure from motion: a new development in photogrammetric measurement. Earth Surface Processes and Landforms 38, 421-430. doi:10.1002/esp.3366.

Furukawa, Y., Ponce, J., 2010. Accurate, dense, and robust multiview stereopsis. Pattern Analysis and Machine Intelligence, IEEE Transactions on 32, 1362-1376. doi:10.1109/TPAMI.2009.161.

Gilbert, G.K., Murphy, E.C., 1914. The transportation of debris by running water. 86, US Government Printing Office.

Girardeau-Montaut, D., 2011. CloudCompare (version 2.6.2): 3D point cloud and mesh processing software. URL: http://www .danielgm.net/cc/. accessed 30 January 2016.

Humphries, R., Venditti, J.G., Sklar, L.S., Wooster, J.K., 2012. Experimental evidence for the effect of hydrographs on sediment pulse 
855 dynamics in gravel-bedded rivers. Water Resources Research 48. 856 doi:10.1029/2011WR010419.

${ }_{857}$ James, M., Robson, S., 2012. Straightforward reconstruction of 3d sur858 faces and topography with a camera: Accuracy and geoscience applica859 tion. Journal of Geophysical Research: Earth Surface (2003-2012) 117. 860 doi:10.1029/2011JF002289.

861

862

Johnson, J.P., Whipple, K.X., 2007. Feedbacks between erosion and sediment transport in experimental bedrock channels. Earth Surface Processes and Landforms 32, 1048-1062. doi:10.1002/esp.1471.

Kasprak, A., Wheaton, J.M., Ashmore, P.E., Hensleigh, J.W., Peirce, S., 2015. The relationship between particle travel distance and channel morphology: Results from physical models of braided rivers. Journal of Geophysical Research: Earth Surface 120, 55-74. doi:10.1002/2014JF003310.

Kim, H.S., Kimura, I., Shimizu, Y., 2015. Bed morphological changes around a finite patch of vegetation. Earth Surface Processes and Landforms 40, 375-388. doi:10.1002/esp.3639.

Kuhnle, R.A., 1993. Incipient motion of sand-gravel sediment mixtures. Jour- 
nal of Hydraulic Engineering 119, 1400-1415. doi:10.1061/(ASCE)07339429(1993)119:12(1400).

Lague, D., Brodu, N., Leroux, J., 2013. Accurate 3d comparison of complex topography with terrestrial laser scanner: Application to the rangitikei canyon (nz). ISPRS Journal of Photogrammetry and Remote Sensing 82, 10-26. doi:10.1016/j.isprsjprs.2013.04.009.

Lane, S., Chandler, J., Porfiri, K., 2001. Monitoring river channel and flume surfaces with digital photogrammetry. Journal of Hydraulic Engineering 127, 871-877. doi:10.1061/(ASCE)0733-9429(2001)127:10(871).

Lane, S., Richards, K., Chandler, J., 1993. Developments in photogrammetry; the geomorphological potential. Progress in Physical Geography 17, $306-328$.

Lanzoni, S., 2000a. Experiments on bar formation in a straight flume. 1. uniform sediment. Water Resources Research 36, 3337-3350. doi:10.1029/2000WR900160.

Lanzoni, S., 2000b. Experiments on bar formation in a straight flume. 2. graded sediment. Water Resources Research 36, 3351-3364. doi:10.1029/2000WR900161. 
890

Leica, 2016.

Leica

HDS3000.

URL: http://hds.leica-geosystems.com/en/5574.htm. accessed 30 January 2016.

Lisle, T.E., Iseya, F., Ikeda, H., 1993. Response of a channel with alternate bars to a decrease in supply of mixed-size bed load: A flume experiment. Water Resources Research 29, 3623-3629. doi:10.1029/93WR01673.

Lowe, D.G., 2004. Distinctive image features from scale-invariant keypoints. International Journal of Computer Vision 60, 91-110. doi:10.1023/B:VISI.0000029664.99615.94.

Marion, A., Tait, S.J., McEwan, I.K., 2003. Analysis of small-scale gravel bed topography during armoring. Water Resources Research 39. doi:10.1029/2003WR002367.

Marra, W.A., Braat, L., Baar, A.W., Kleinhans, M.G., 2014. Valley formation by groundwater seepage, pressurized groundwater outbursts and crater-lake overflow in flume experiments with implications for mars. Icarus 232, 97-117. doi:10.1016/j.icarus.2013.12.026.

Marzolff, I., Poesen, J., 2009. The potential of 3d gully monitoring with gis 
using high-resolution aerial photography and a digital photogrammetry system. Geomorphology 111, 48-60. doi:10.1016/j.geomorph.2008.05.047.

Micheletti, N., Chandler, J.H., Lane, S.N., 2015. Investigating the geomorphological potential of freely available and accessible structure-frommotion photogrammetry using a smartphone. Earth Surface Processes and Landforms 40, 473-486. doi:10.1002/esp.3648.

Nelson, P.A., Brew, A.K., Morgan, J.A., 2015. Morphodynamic response of a variable-width channel to changes in sediment supply. Water Resources Research 51, 5717-5734. doi:10.1002/2014WR016806.

Nelson, P.A., Dietrich, W.E., Venditti, J.G., 2010. Bed topography and the development of forced bed surface patches. Journal of Geophysical Research 115. doi:10.1029/2010JF001747.

Nelson, P.A., Venditti, J.G., Dietrich, W.E., Kirchner, J.W., Ikeda, H., Iseya, F., Sklar, L.S., 2009. Response of bed surface patchiness to reductions in sediment supply. Journal of Geophysical Research 114. doi:10.1029/2008JF001144.

Nouwakpo, S.K., James, M.R., Weltz, M.A., Huang, C.H., Chagas, I., Lima, L., 2014. Evaluation of structure from motion for soil micro- 
topography measurement. The Photogrammetric Record 29, 297-316. doi:10.1111/phor.12072.

Paschotta, R., 2008. Encyclopedia of Laser Physics and Technology. volume 1. Wiley-VCH: Weinheim, Germany.

Peter Heng, B., Chandler, J.H., Armstrong, A., 2010. Applying close range digital photogrammetry in soil erosion studies. The Photogrammetric Record 25, 240-265. doi:10.1111/j.1477-9730.2010.00584.x.

Prosdocimi, M., Calligaro, S., Sofia, G., Dalla Fontana, G., Tarolli, P., 2015. Bank erosion in agricultural drainage networks: new challenges from structure-from-motion photogrammetry for post-event analysis. Earth Surface Processes and Landforms 40, 1891-1906. doi:10.1002/esp.3767.

Qin, J., Ng, S.L., 2012. Estimation of effective roughness for waterworked gravel surfaces. Journal of Hydraulic Engineering 138, 923-934. doi:10.1061/(ASCE)HY.1943-7900.0000610.

Ramos, P.X., Bento, A.M., Maia, R., Pêgo, J.P., 2015. Characterization of the scour cavity evolution around a complex bridge pier. Journal of Applied Water Engineering and Research , 110doi:10.1080/23249676.2015.1090353. 
Schumm, S., Khan, H., 1972. Experimental study of channel patterns. Geological Society of America Bulletin 83, 1755-1770. doi:10.1130/00167606(1972)83[1755:ESOCP]2.0.CO;2.

Sklar, L.S., Fadde, J., Venditti, J.G., Nelson, P., Wydzga, M.A., Cui, Y., Dietrich, W.E., 2009. Translation and dispersion of sediment pulses in flume experiments simulating gravel augmentation below dams. Water Resources Research 45. doi:10.1029/2008WR007346.

Smith, M., Carrivick, J., Quincey, D., 2015. Structure from motion photogrammetry in physical geography. Progress in Physical Geography , 1-29doi:10.1177/0309133315615805.

Smith, M., Vericat, D., 2014. Evaluating shallow-water bathymetry from through-water terrestrial laser scanning under a range of hydraulic and physical water quality conditions. River Research and Applications 30, 905-924. doi:10.1111/phor.12072.

Smith, M.W., Vericat, D., 2015. From experimental plots to experimental landscapes: topography, erosion and deposition in sub-humid badlands from structure-from-motion photogrammetry. Earth Surface Processes and Landforms doi:10.1002/esp.3747. 
Snavely, N., Seitz, S.M., Szeliski, R., 2006. Photo tourism: exploring photo collections in 3d, in: ACM transactions on graphics (TOG), ACM. pp. 835-846. doi:10.1145/1179352.1141964.

Stojic, M., Chandler, J., Ashmore, P., Luce, J., 1998. The assessment of sediment transport rates by automated digital photogrammetry. Photogrammetric Engineering and Remote Sensing 64, 387-395.

Tingdahl, D., Van Gool, L., 2011. A public system for image based 3d model generation, in: Computer Vision/Computer Graphics Collaboration Techniques. Springer, pp. 262-273. doi:10.1007/978-3-642-24136-9_23.

Ullman, S., 1979. The interpretation of structure from motion. Proceedings of the Royal Society of London B: Biological Sciences 203, 405-426. doi:10.1098/rspb.1979.0006.

Venditti, J.G., Lin, C.Y.M., Kazemi, M., 2015. Variability in bedform morphology and kinematics with transport stage. Sedimentology 63, 10171040. doi:10.1111/sed.12247.

Venditti, J.G., Nelson, P.A., Minear, J.T., Wooster, J., Dietrich, W.E., 2012. Alternate bar response to sediment supply termination. Journal of Geophysical Research doi:10.1029/2011JF002254. 
979

Wackrow, R., Chandler, J.H., 2008. A convergent image configuration for dem extraction that minimises the systematic effects caused by an inaccurate lens model. The Photogrammetric Record 23, 6-18. doi:10.1111/j.1477-9730.2008.00467.x.

Wackrow, R., Chandler, J.H., 2011. Minimising systematic error surfaces in digital elevation models using oblique convergent imagery. The Photogrammetric Record 26, 16-31. doi:10.1111/j.1477-9730.2011.00623.x.

Wang, C., Wang, Q., Meire, D., Ma, W., Wu, C., Meng, Z., Van de Koppel, J., Troch, P., Verhoeven, R., De Mulder, T., et al., 2016. Biogeomorphic feedback between plant growth and flooding causes alternative stable states in an experimental floodplain. Advances in Water Resources 93, 223-235. doi:10.1016/j.advwatres.2015.07.003.

Westoby, M., Brasington, J., Glasser, N., Hambrey, M., Reynolds, J., 2012. structure-from-motionphotogrammetry: A low-cost, effective tool for geoscience applications. Geomorphology 179, 300-314. doi:10.1016/j.geomorph.2012.08.021.

Wu, C., 2013. Towards linear-time incremental structure from motion, in: 
9962013 International Conference on 3D Vision-3DV 2013, IEEE. pp. 127-134. 997 doi:10.1109/3DV.2013.25.

${ }_{998}$ Wu, C., Agarwal, S., Curless, B., Seitz, S.M., 2011. Multicore bundle adjust999 ment, in: 2011 IEEE Conference on Computer Vision and Pattern Recog1000 nition (CVPR), IEEE. pp. 3057-3064. doi:10.1109/CVPR.2011.5995552. 
Table 1: Dimensions of the flumes used to compare TLS and SfM as well as their grain size distribution medians $\left(D_{50}\right)$ and geometric standard deviations $\left(\sigma_{g}\right)$. These dimensions do not correspond to the dimensions used in the point cloud comparisons.

\begin{tabular}{cccccc}
\hline \hline Flume & Total width $(\mathrm{m})$ & Total length $(\mathrm{m})$ & Approx. depth $(\mathrm{m})$ & $D_{50}(\mathrm{~mm})$ & $\sigma_{g}(\mathrm{~mm})$ \\
\hline 1 & 0.22 & 9.14 & 0.38 & 1.5 & 2.74 \\
2 & 1.22 & 9.14 & 0.58 & 31.0 & 4.33 \\
3 & 1.22 & 18.29 & 0.66 & 4.1 & 2.00 \\
4 & 4.88 & 15.24 & 1.20 & 6.2 & 1.67 \\
5 & 6.71 & 30.48 & 0.78 & 0.2 & 1.37 \\
\hline \hline
\end{tabular}




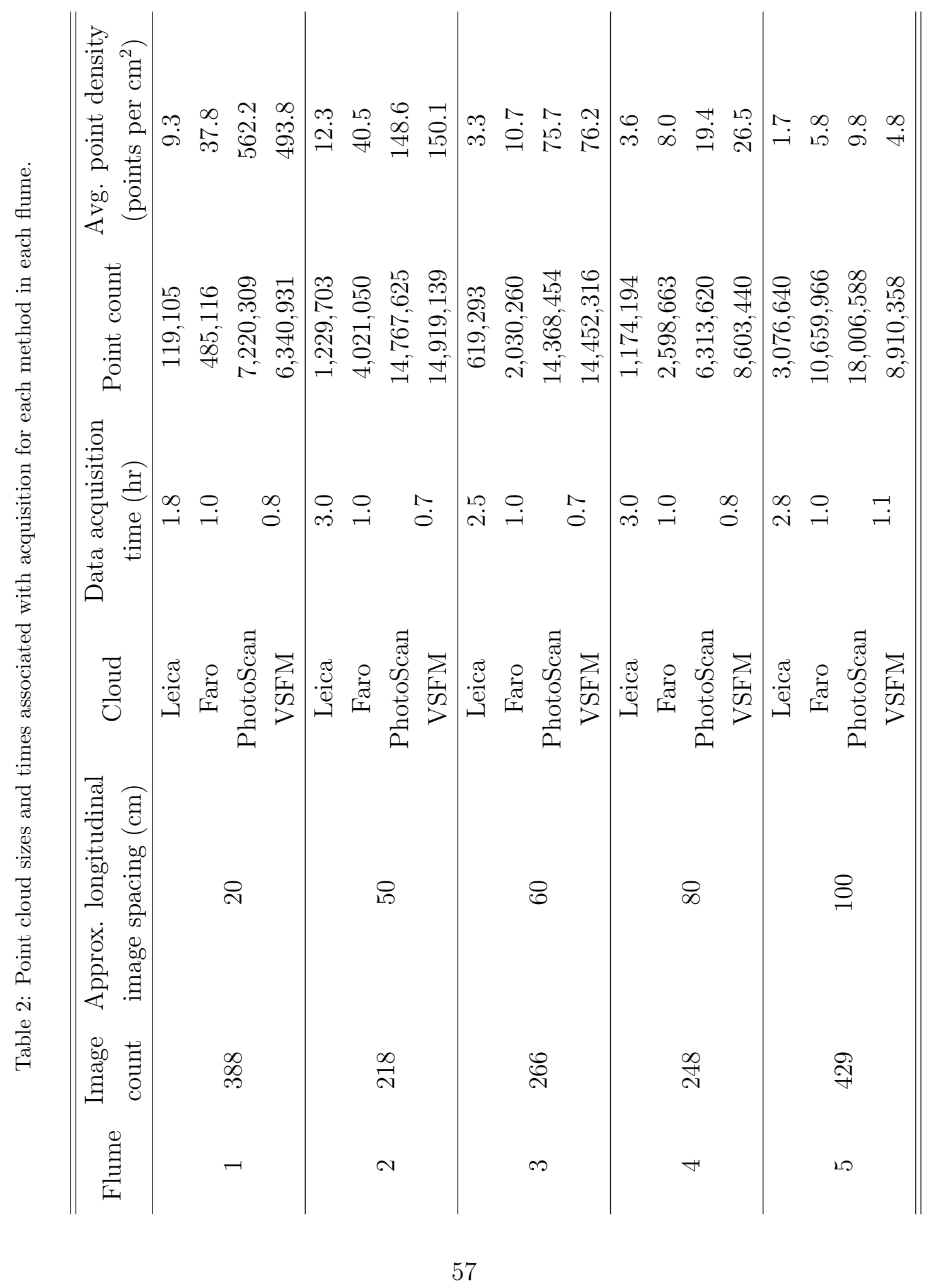


Table 3: Point cloud elevation and roughness values for each method in each flume.

\begin{tabular}{|c|c|c|c|c|c|c|c|}
\hline \multirow{2}{*}{ Flume } & \multirow{2}{*}{ Cloud } & \multicolumn{2}{|c|}{ Elevation $(\mathrm{cm})$} & \multirow{2}{*}{ Rugosity } & \multicolumn{3}{|c|}{ Roughness index-elevation $(\mathrm{cm})$} \\
\hline & & Range & Std. dev. & & Range & Median & Std. dev. \\
\hline \multirow{4}{*}{1} & Leica & 9.4 & 0.8 & 1.42 & 0.8 & 0.1 & 0.1 \\
\hline & Faro & 17.4 & 1.5 & 1.61 & 1.5 & 0.1 & 0.2 \\
\hline & PhotoScan & 11.8 & 1.2 & 1.26 & 1.2 & 0.1 & 0.1 \\
\hline & VSFM & 10.7 & 1.4 & 1.62 & 1.3 & 0.1 & 0.2 \\
\hline \multirow{4}{*}{2} & Leica & 43.3 & 6.4 & 4.11 & 7.3 & 1.0 & 0.6 \\
\hline & Faro & 52.1 & 8.3 & 6.09 & 7.1 & 1.1 & 0.7 \\
\hline & PhotoScan & 46.2 & 7.2 & 5.73 & 6.9 & 1.0 & 0.7 \\
\hline & VSFM & 51.4 & 6.6 & 6.77 & 11.1 & 1.2 & 0.7 \\
\hline \multirow{4}{*}{3} & Leica & 25.7 & 4.2 & 1.19 & 1.1 & 0.2 & 0.1 \\
\hline & Faro & 25.6 & 4.3 & 1.27 & 1.3 & 0.2 & 0.2 \\
\hline & PhotoScan & 25.5 & 5.1 & 1.12 & 1.2 & 0.2 & 0.1 \\
\hline & VSFM & 26.6 & 5.0 & 1.97 & 1.3 & 0.2 & 0.1 \\
\hline \multirow{4}{*}{4} & Leica & 4.7 & 0.7 & 1.16 & 0.4 & 0.1 & 0.0 \\
\hline & Faro & 7.0 & 0.8 & 1.15 & 0.4 & 0.1 & 0.0 \\
\hline & PhotoScan & 4.2 & 0.6 & 1.06 & 0.4 & 0.1 & 0.0 \\
\hline & VSFM & 14.6 & 0.9 & 4.22 & 1.4 & 0.3 & 0.2 \\
\hline \multirow{4}{*}{5} & Leica & 51.5 & 11.1 & 1.08 & 1.6 & 0.1 & 0.1 \\
\hline & Faro & 52.4 & 11.2 & 1.09 & 3.0 & 0.1 & 0.1 \\
\hline & PhotoScan & 53.2 & 12.3 & 1.14 & 9.7 & 0.1 & 0.1 \\
\hline & VSFM & 64.5 & 9.0 & 1.78 & 12.6 & 0.3 & 0.4 \\
\hline
\end{tabular}


Table 4: Image combinations comparison for Flume 3.

\begin{tabular}{cccccc}
\hline \hline & & & & \multicolumn{2}{c}{ M3C2 distances from Leica (m) } \\
\cline { 5 - 6 } Image combination & Targets & Image count & Point count & Median & RMS \\
\hline All images (JPG) & no & 266 & $14,368,454$ & 0.001 & 0.002 \\
All images (RAW) & no & 266 & $14,091,686$ & 0.001 & 0.002 \\
All images (JPG) & yes & 266 & $14,353,849$ & 0.001 & 0.002 \\
US-DS images & yes & 89 & $11,307,633$ & 0.000 & 0.002 \\
RB-LB images & no & 177 & $14,231,567$ & 0.001 & 0.002 \\
RB-LB images & yes & 177 & $14,263,685$ & 0.001 & 0.002 \\
RB-LB angled & no & 117 & $12,278,775$ & 0.001 & 0.002 \\
No cross flume & no & 206 & $12,939,702$ & 0.000 & 0.002 \\
Every second & no & 135 & $13,862,586$ & 0.001 & 0.002 \\
Every third & no & 90 & - & - & - \\
Every fourth & no & 71 & - & - & - \\
\hline \hline
\end{tabular}


Table 5: Image combinations comparison for Flume 5.

\begin{tabular}{cccccc}
\hline \hline & & & & \multicolumn{2}{c}{ M3C2 distances from Leica (m) } \\
\cline { 5 - 6 } Image combination & Targets & Image count & Point count & Median & RMS \\
\hline All images (JPG) & no & 429 & $18,006,588$ & 0.000 & 0.003 \\
All images (RAW) & no & 429 & $9,199,483$ & 0.004 & 0.015 \\
All images (JPG) & yes & 429 & $20,163,866$ & 0.000 & 0.004 \\
US-DS images & yes & 94 & $8,544,152$ & -0.001 & 0.004 \\
RB-LB images & no & 335 & $22,732,148$ & 0.000 & 0.003 \\
RB-LB images & yes & 335 & $24,198,759$ & 0.000 & 0.003 \\
RB-LB angled & no & 134 & $19,155,313$ & 0.000 & 0.009 \\
No cross flume & no & 362 & $19,425,883$ & 0.000 & 0.004 \\
Every second & no & 223 & $14,776,760$ & 0.000 & 0.004 \\
Every third & no & 146 & $8,597,343$ & 0.006 & 0.024 \\
Every fourth & no & 114 & - & - & - \\
\hline \hline
\end{tabular}

Table 6: Flume 3 point cloud summaries produced using different PhotoScan settings.

Processing times should be taken as "order of magnitude" approximations for a standard desktop computer.

\begin{tabular}{cccccc}
\hline \hline & & & \multicolumn{2}{l}{ M3C2 distances from Leica $(\mathrm{m})$} & \\
\cline { 4 - 5 } Accuracy & Quality & Point count & Median & RMS & Processing time \\
\hline Lowest & Medium & $15,961,002$ & 0.001 & 0.003 & hours \\
Medium & Medium & $14,353,407$ & 0.001 & 0.002 & hours \\
Highest & Lowest & 794,090 & 0.001 & 0.003 & minutes \\
Highest & Medium & $14,368,454$ & 0.001 & 0.002 & hours \\
Highest & Ultra High & $262,402,248$ & 0.000 & 0.002 & days \\
\hline \hline
\end{tabular}




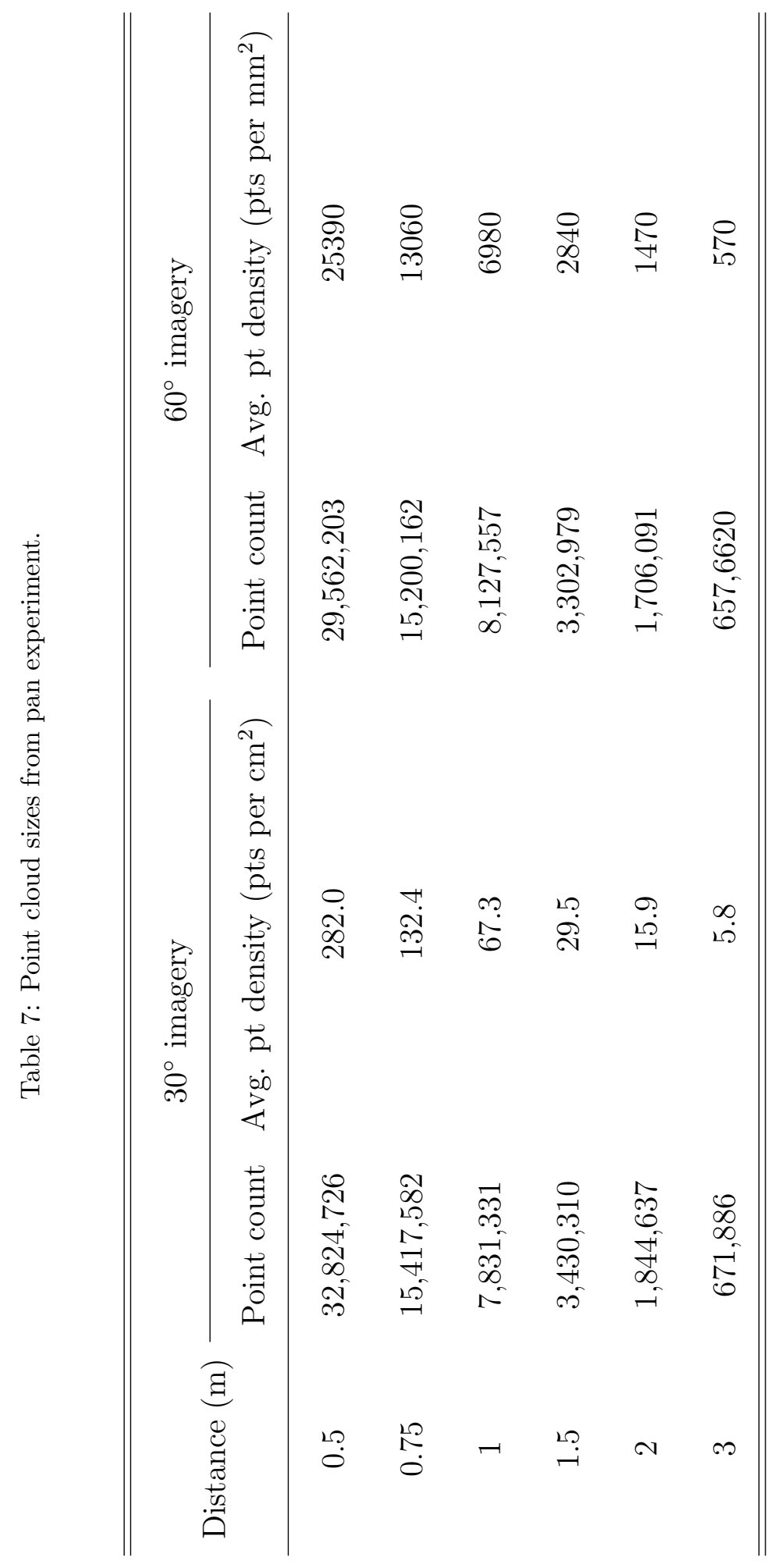

61 


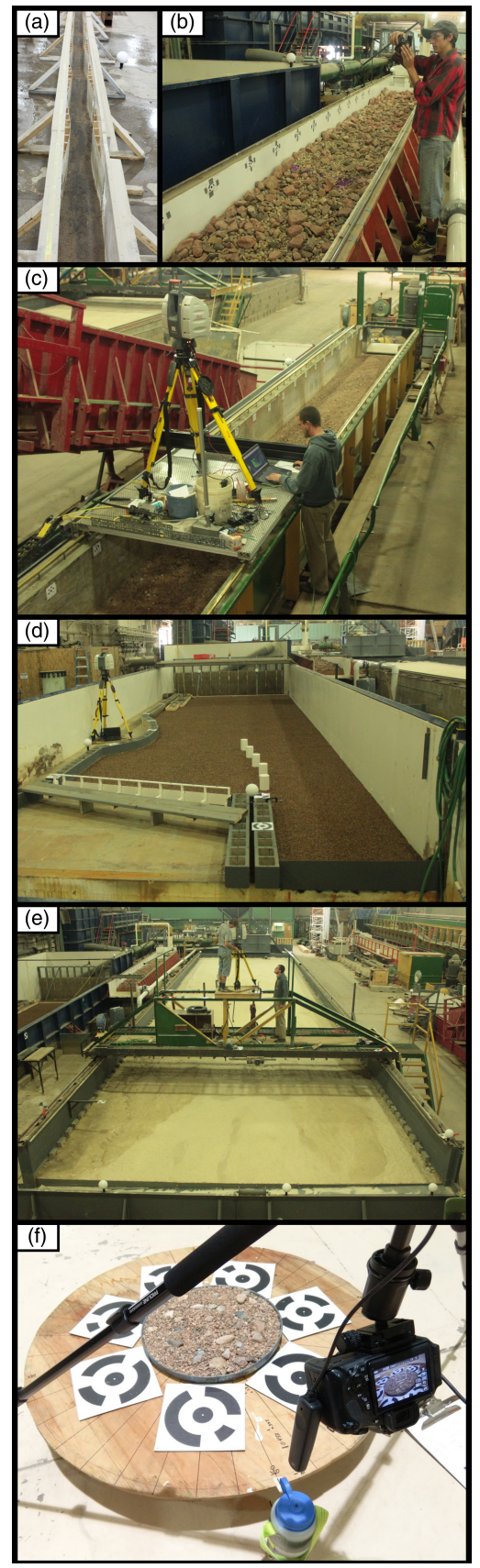

Figure 1: Photographs showing the setup and grain sizes for (a) Flume 1, (b) Flume 2, (c) Flume 3, (d) Flume 4, (e) Flume 5, and (f) the pan. 


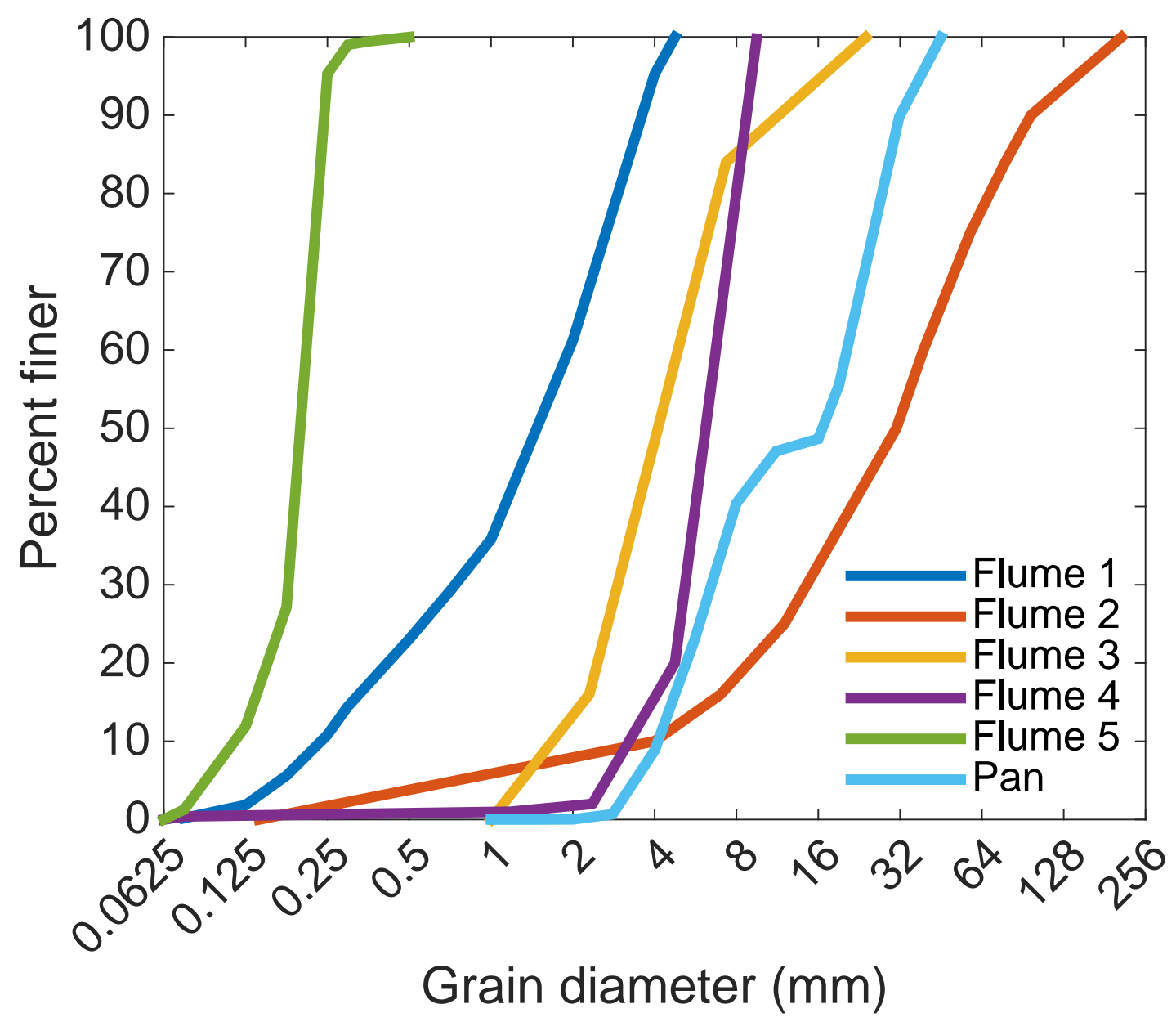

Figure 2: Surface grain size distributions present in each flume. 
(a)

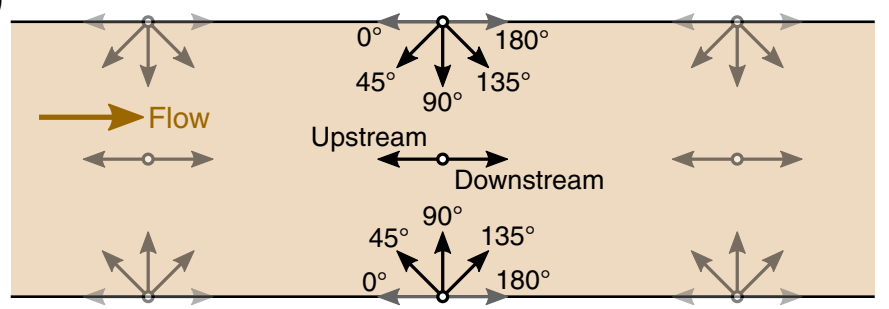

(b)

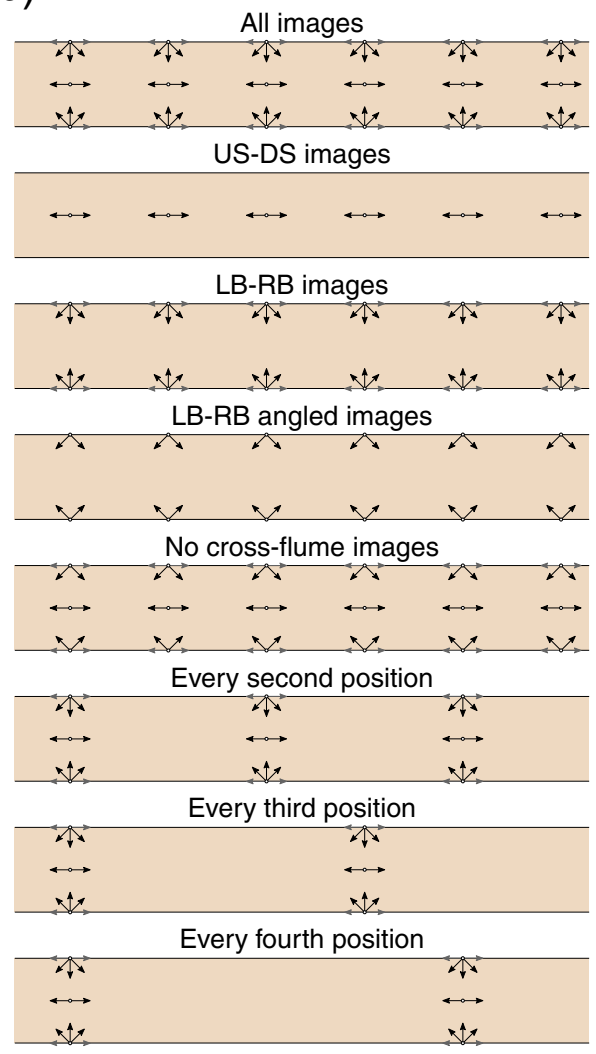

(c)

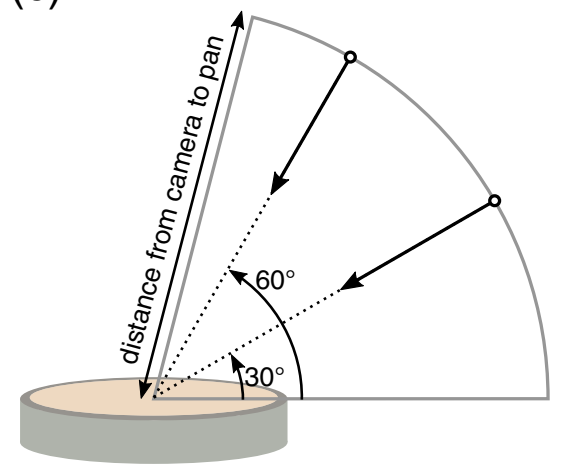

(d)

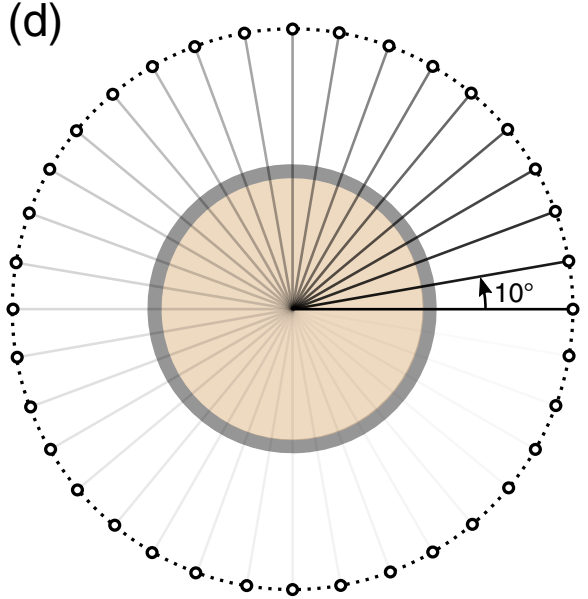

Figure 3: Conceptual illustrations showing (a) the approximate camera angles for flume imagery, (b) the different combinations of images tested for Flumes 3 and 5, (c) the vertical angles for the pan imagery, and (d) the horizontal angles for the pan imagery. 


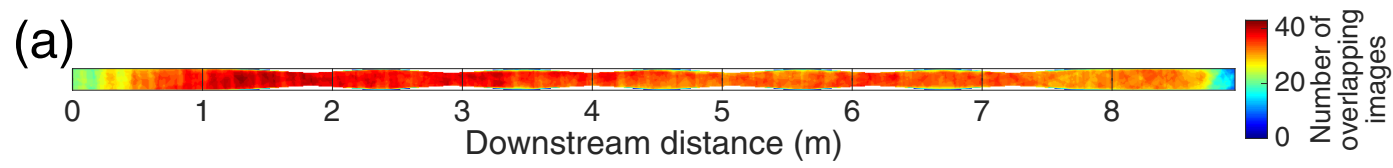

(b)

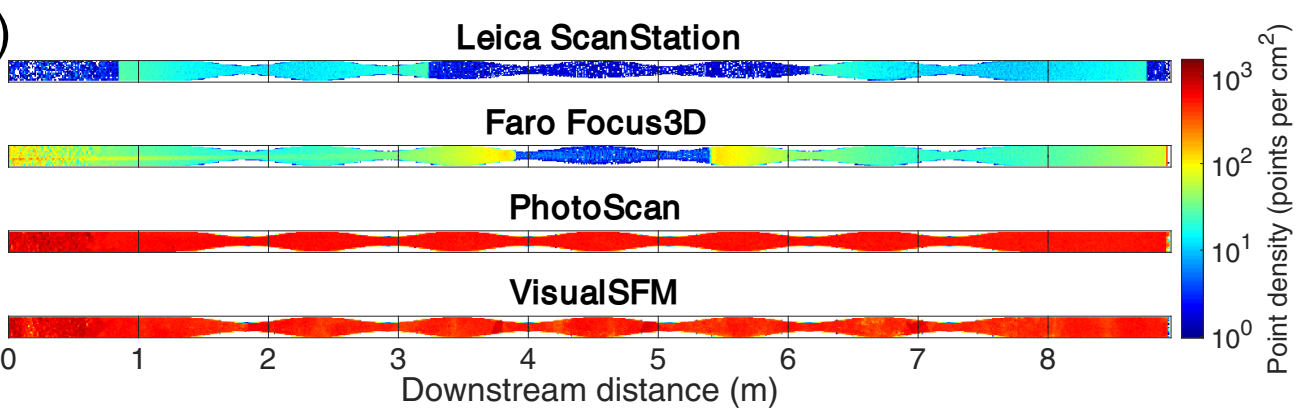

(c)

Leica ScanStation

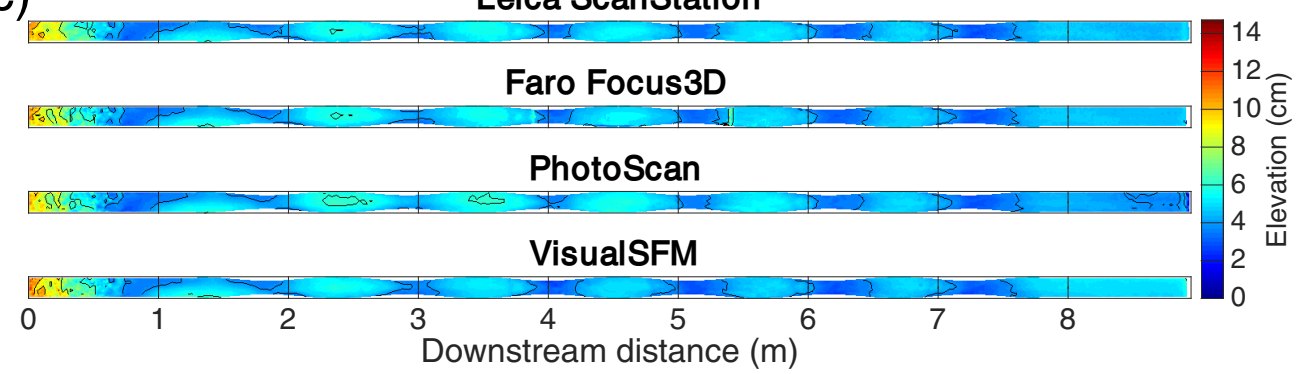

(d)

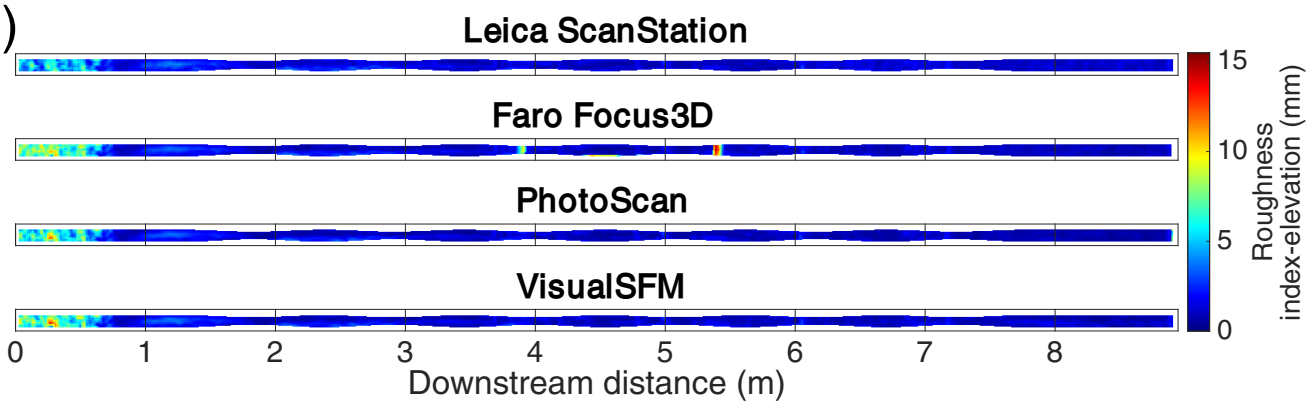

Figure 4: Flume 1 maps showing (a) image overlap count for all images collected for SfM and (b) point density, (c) elevation, and (d) roughness index-elevation for Leica ScanStation, Faro Focus3D, PhotoScan and VisualSFM models. 

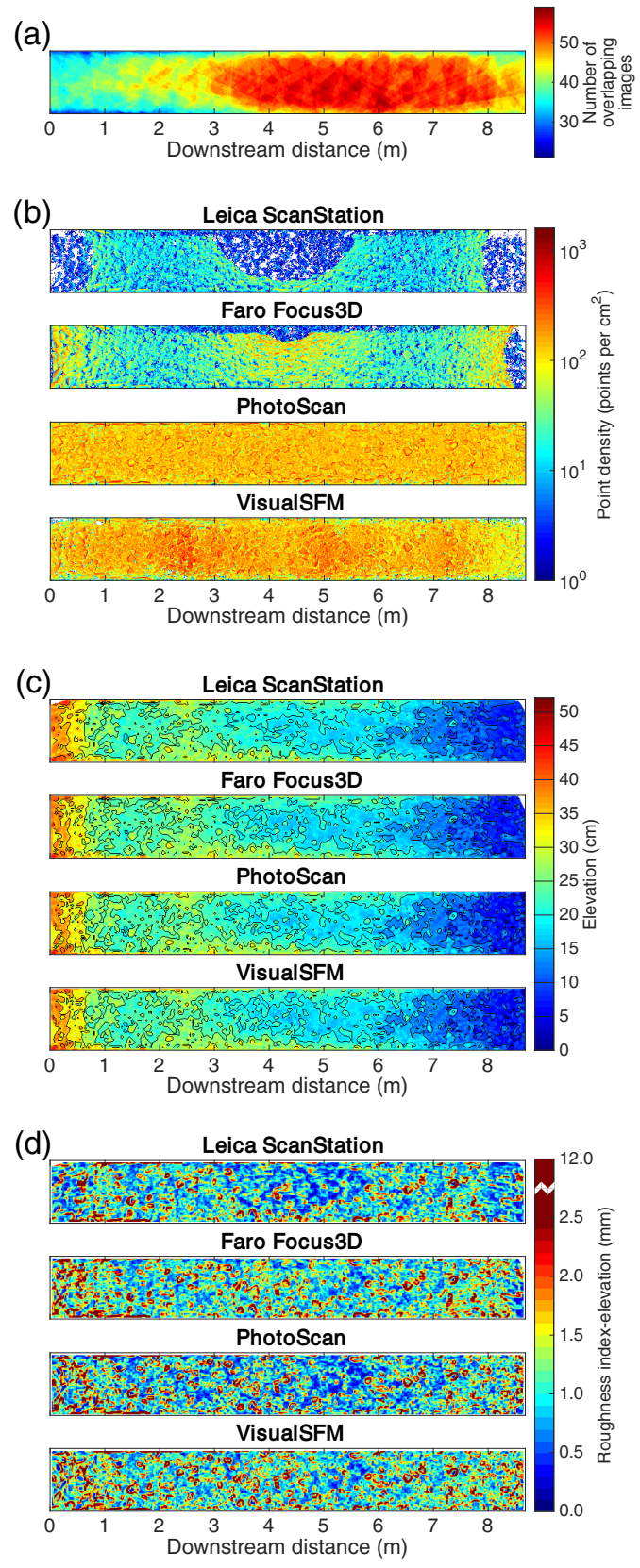

Figure 5: Flume 2 maps showing (a) image overlap count for all images collected for SfM and (b) point density, (c) elevation, and (d) roughness index-elevation for Leica ScanStation, Faro Focus3D, PhotoScan and VisualSFM models. 
(a)

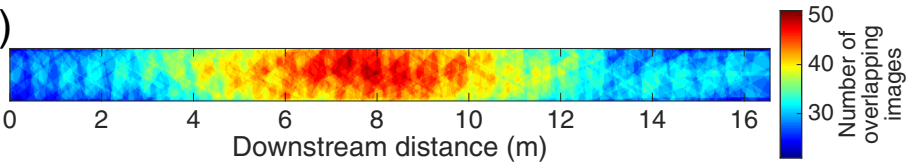

(b)

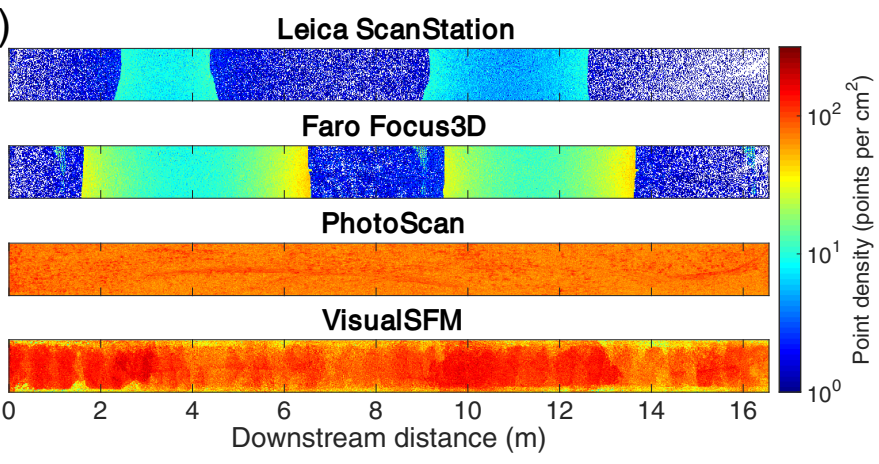

(c)

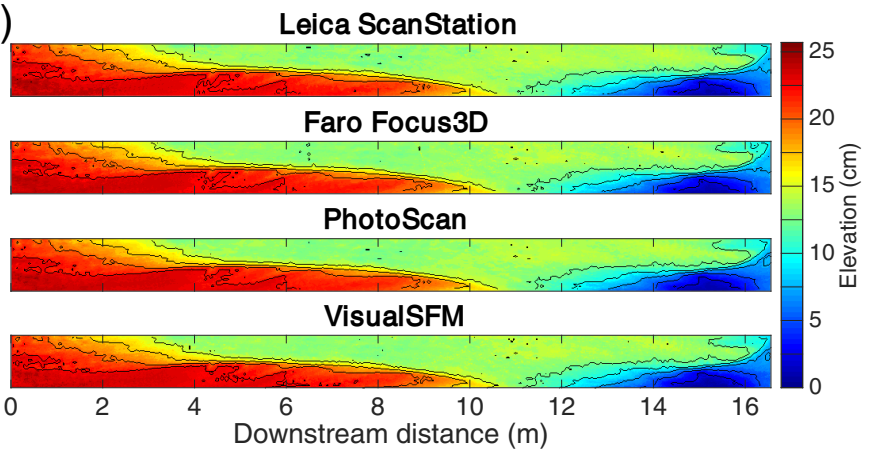

(d)

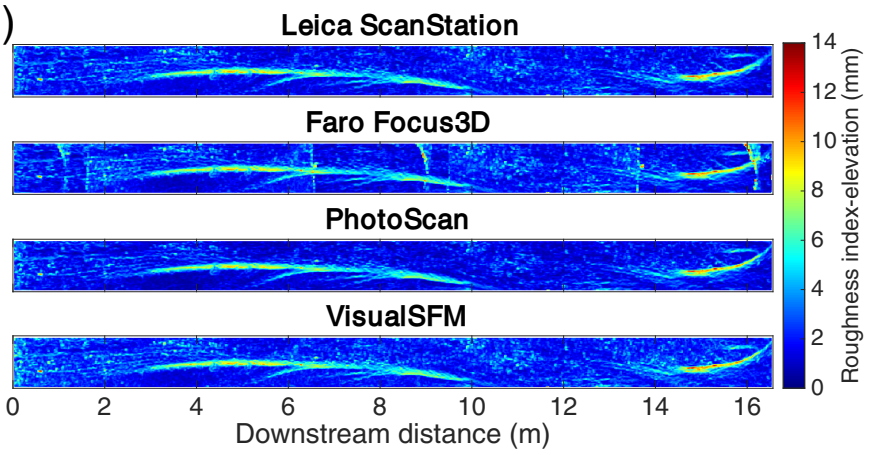

Figure 6: Flume 3 maps showing (a) image overlap count for all images collected for SfM and (b) point density, (c) elevation, and (d) roughness index-elevation for Leica ScanStation, Faro Focus3D, PhotoScan and VisualSFM models. 

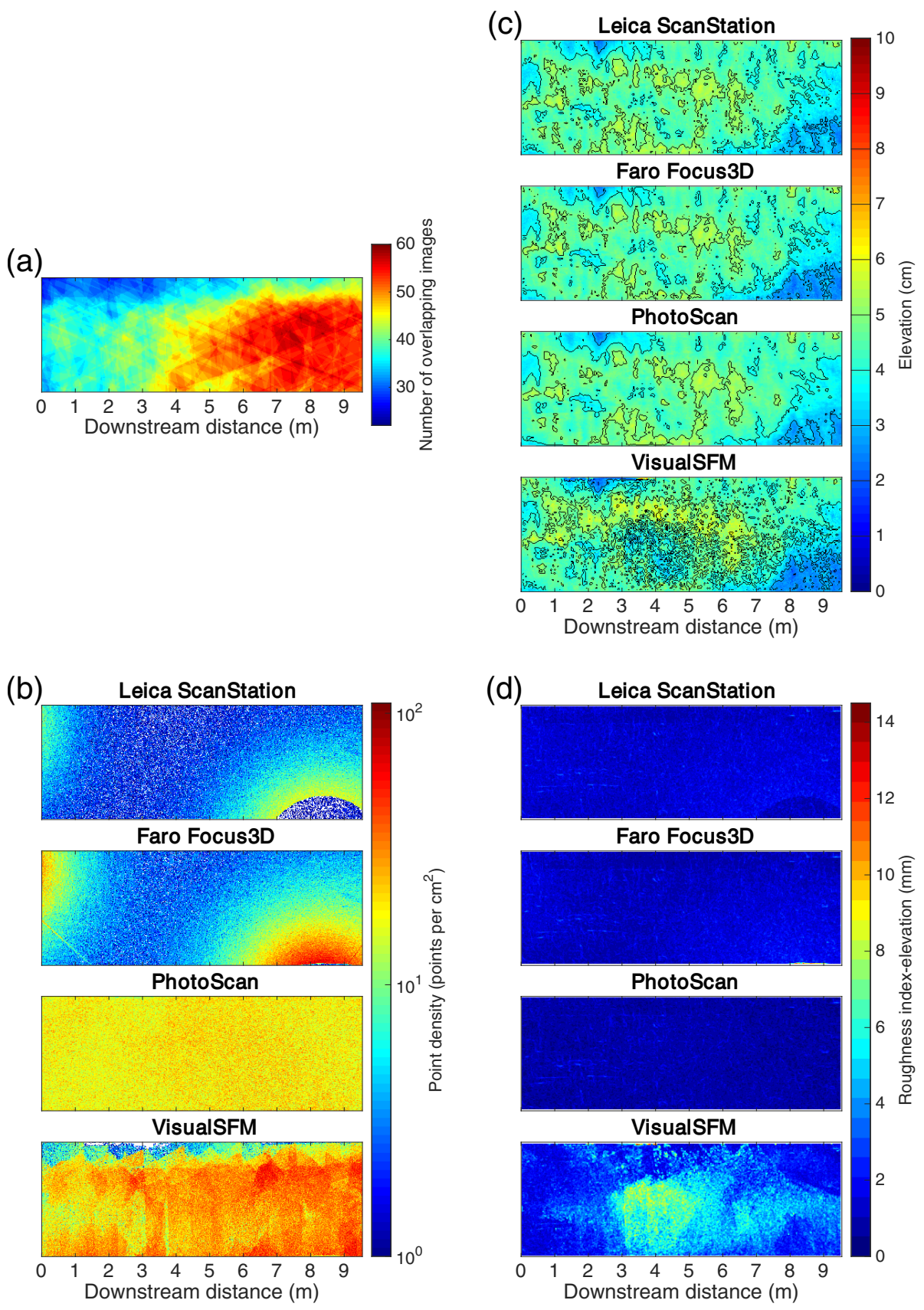

Figure 7: Flume 4 maps showing (a) image overlap count for all images collected for SfM and (b) point density, (c) elevation, and (d) roughness index-elevation for Leica ScanStation, Faro Focus3D, PhotoScan and VisualSFM models. 
(a)

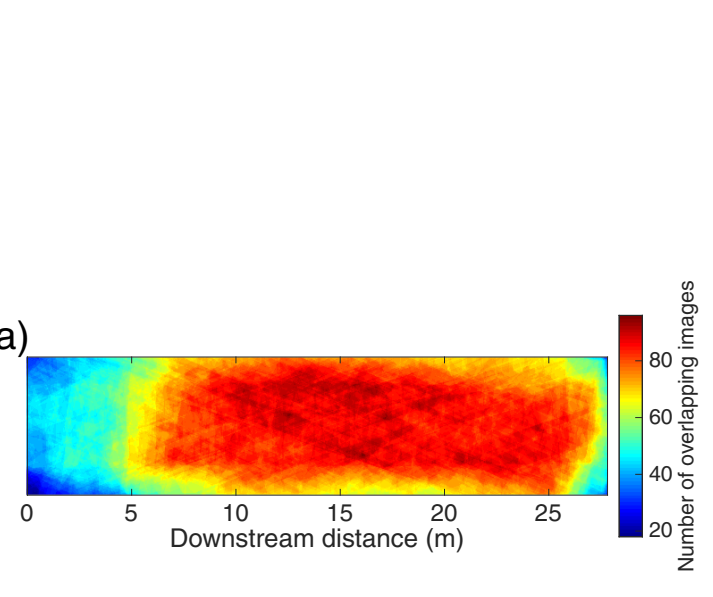

(b)

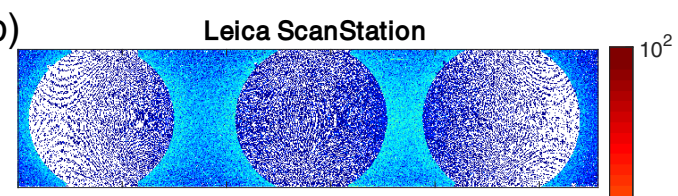

Faro Focus3D

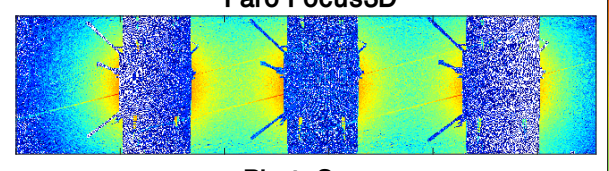

PhotoScan

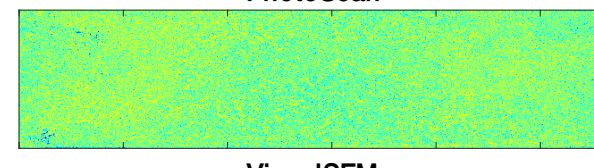

VisualSFM

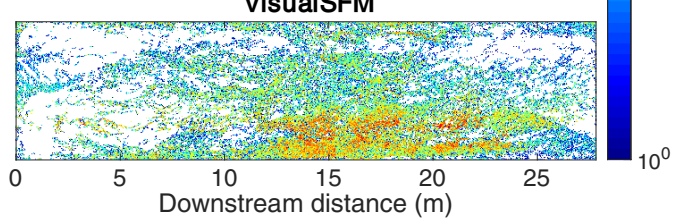

(c)

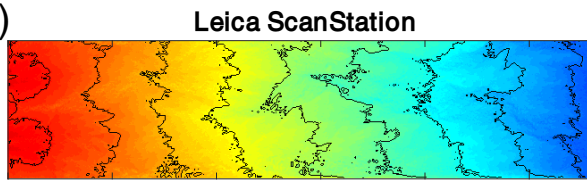

Faro Focus3D

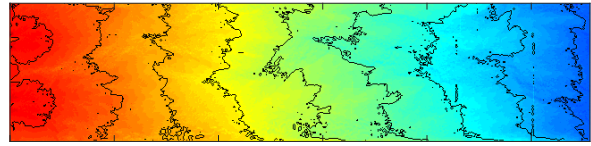

PhotoScan

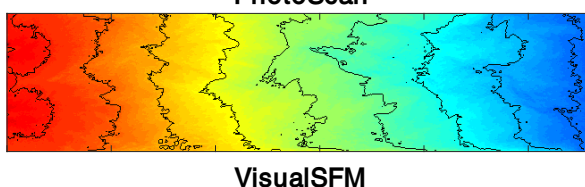

VisualSFM

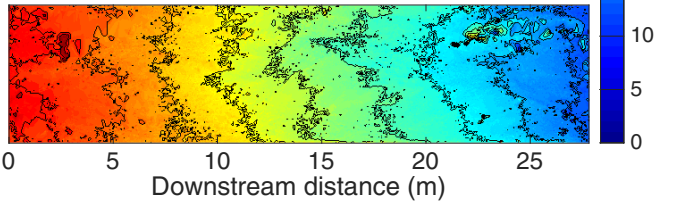

(d)

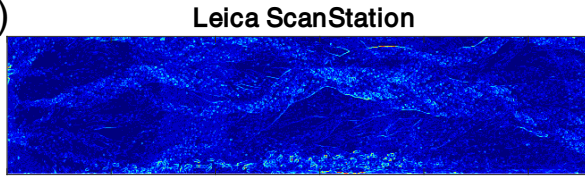

Faro Focus3D

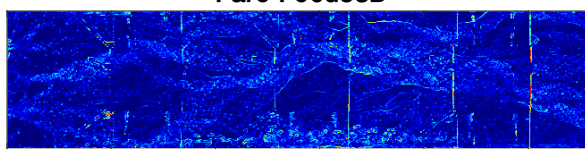

PhotoScan

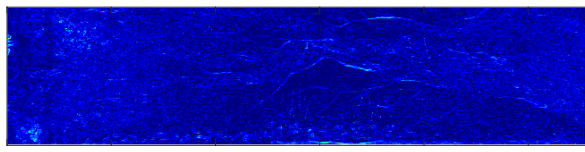

VisualSFM

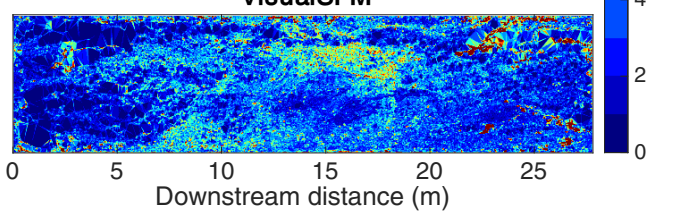

Figure 8: Flume 5 maps showing (a) image overlap count for all images collected for SfM and (b) point density, (c) elevation, and (d) roughness index-elevation for Leica ScanStation, Faro Focus3D, PhotoScan and VisualSFM models. 


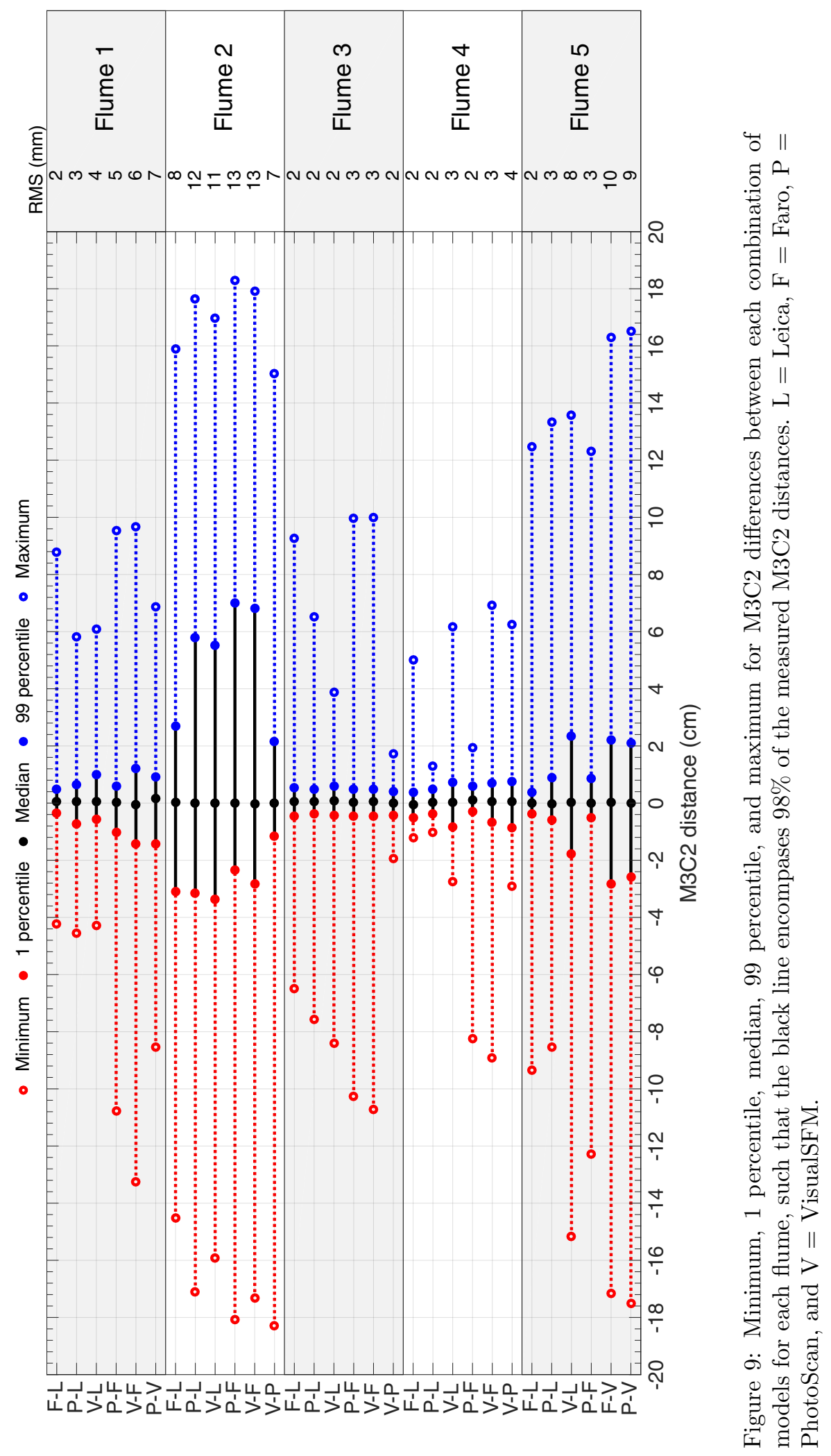




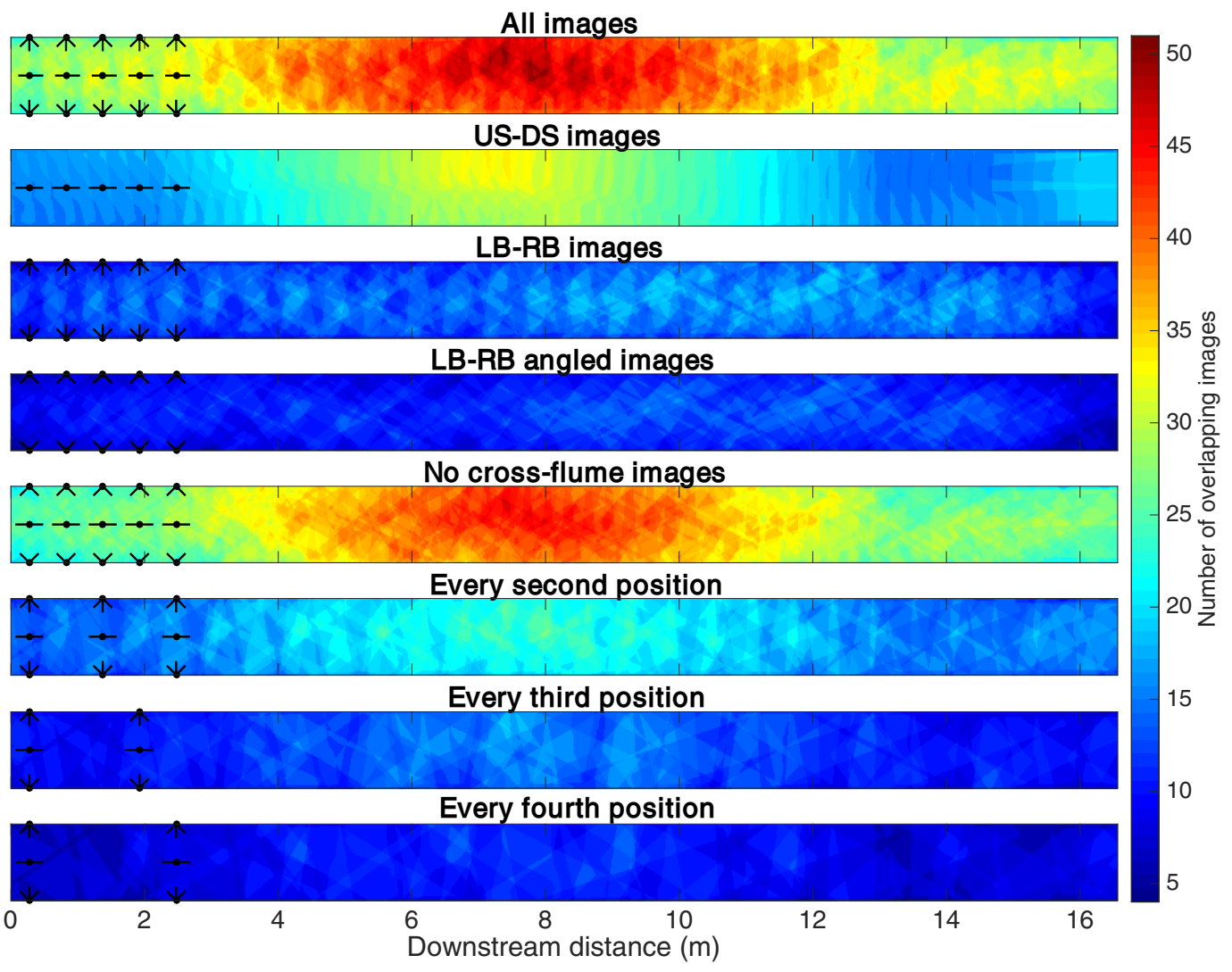

Figure 10: Flume 3 maps showing the count of overlapping images for each of the image combinations. Note that camera positions and directions indicated by the black dots and lines are for illustrative purposes only and do not represent actual image positions and angles. 


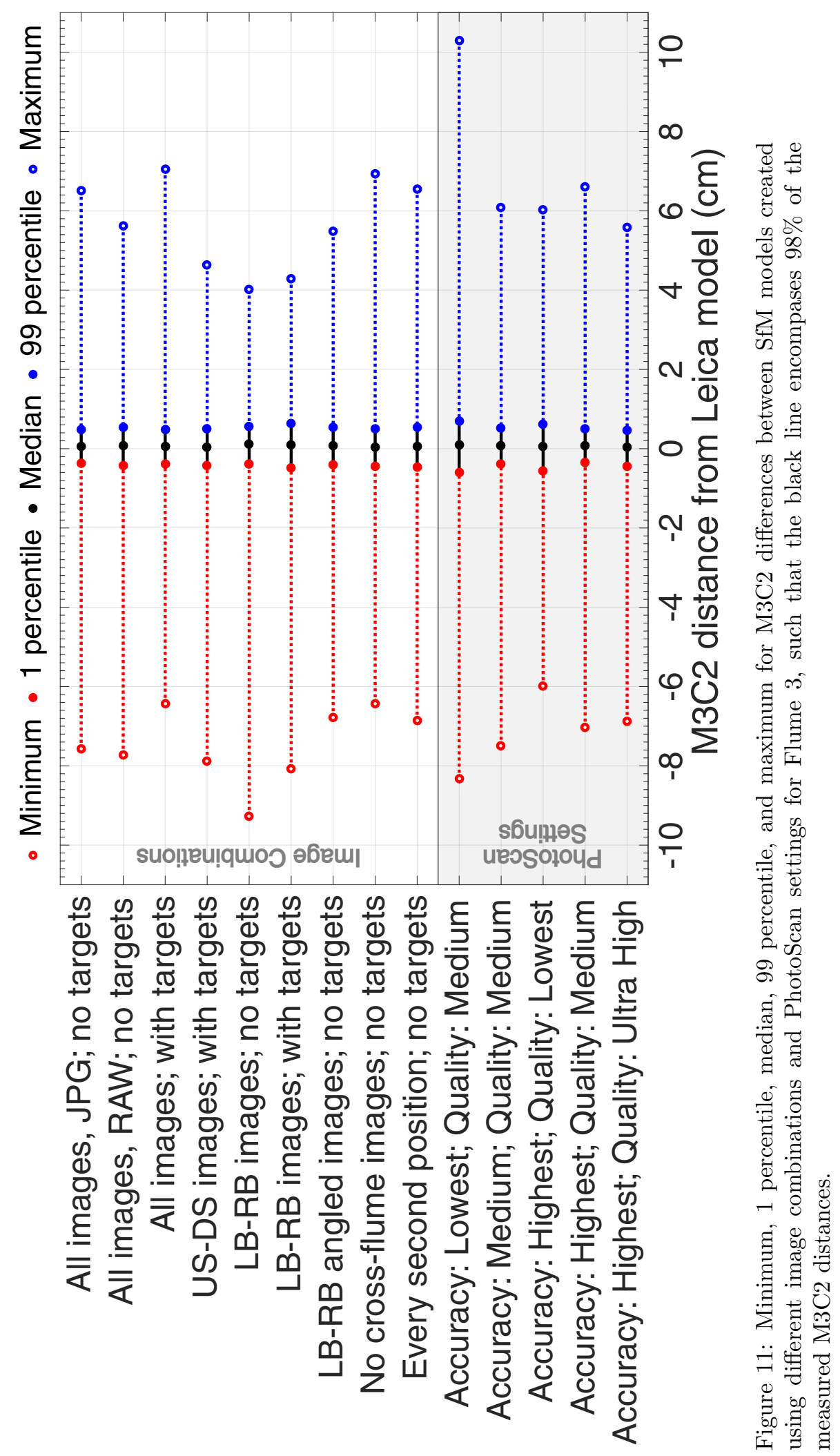



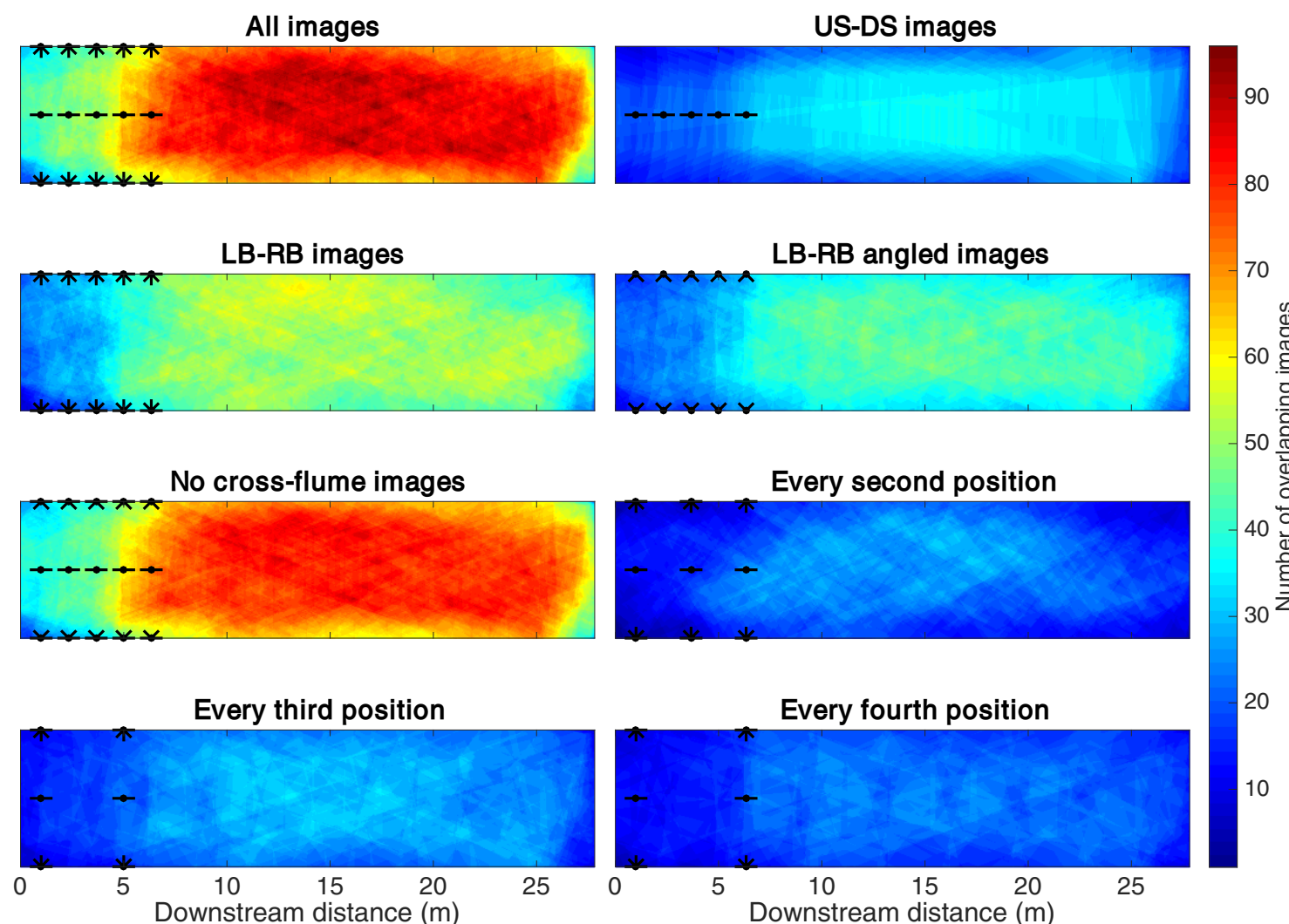

Figure 12: Flume 5 maps showing the count of overlapping images for each of the image combinations. Note that camera positions and directions indicated by the black dots and lines are for illustrative purposes only and do not represent actual image positions and angles. 


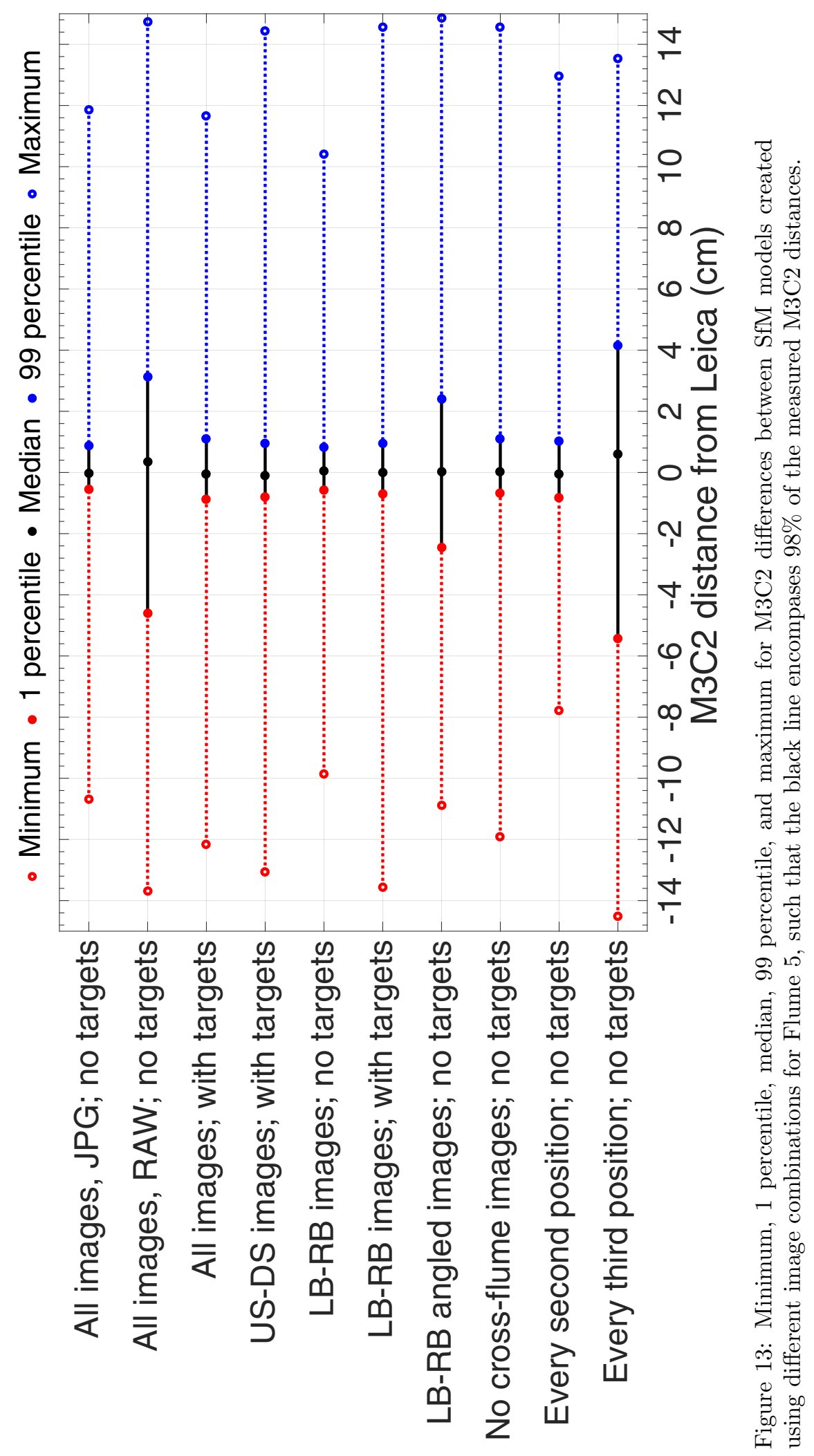




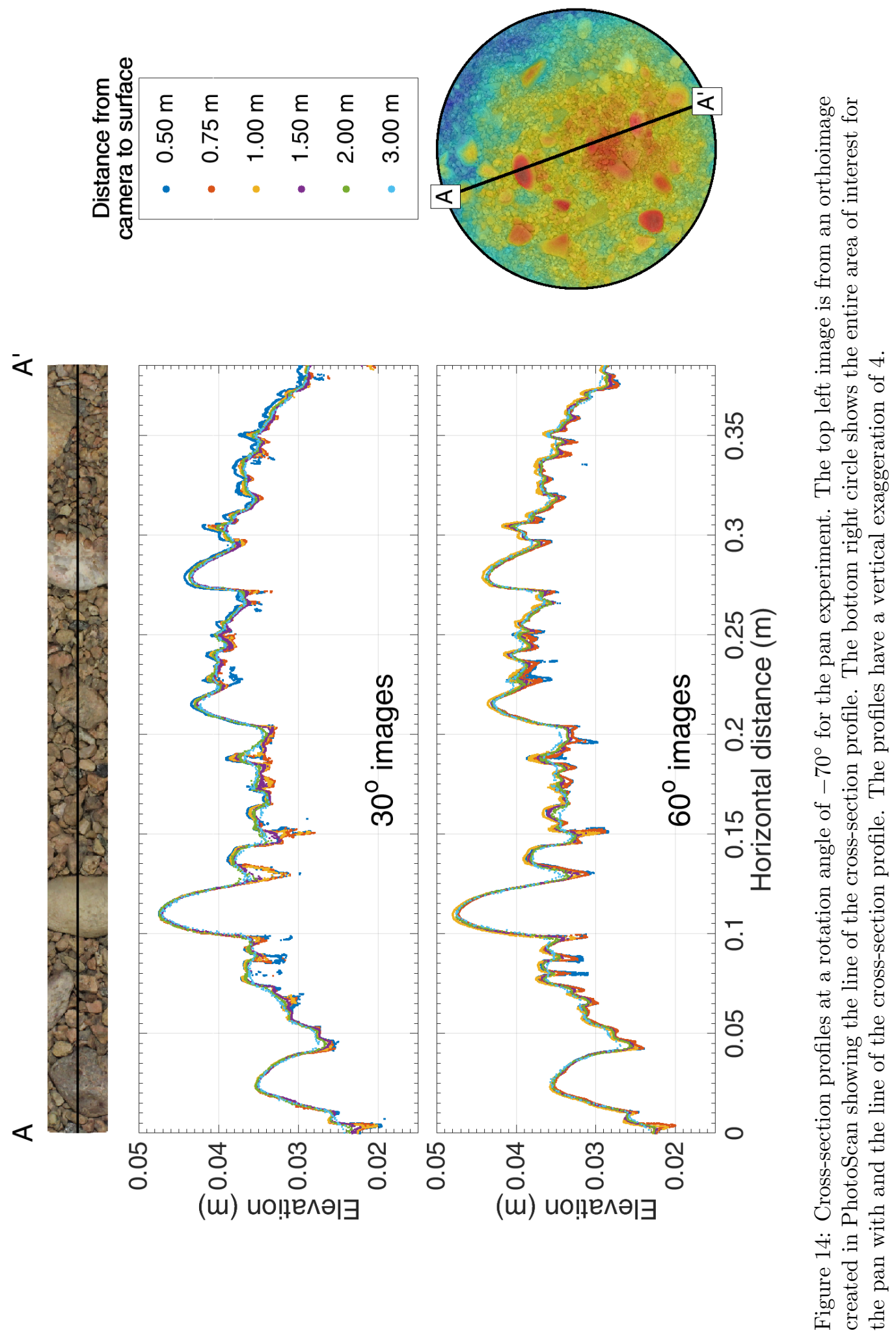




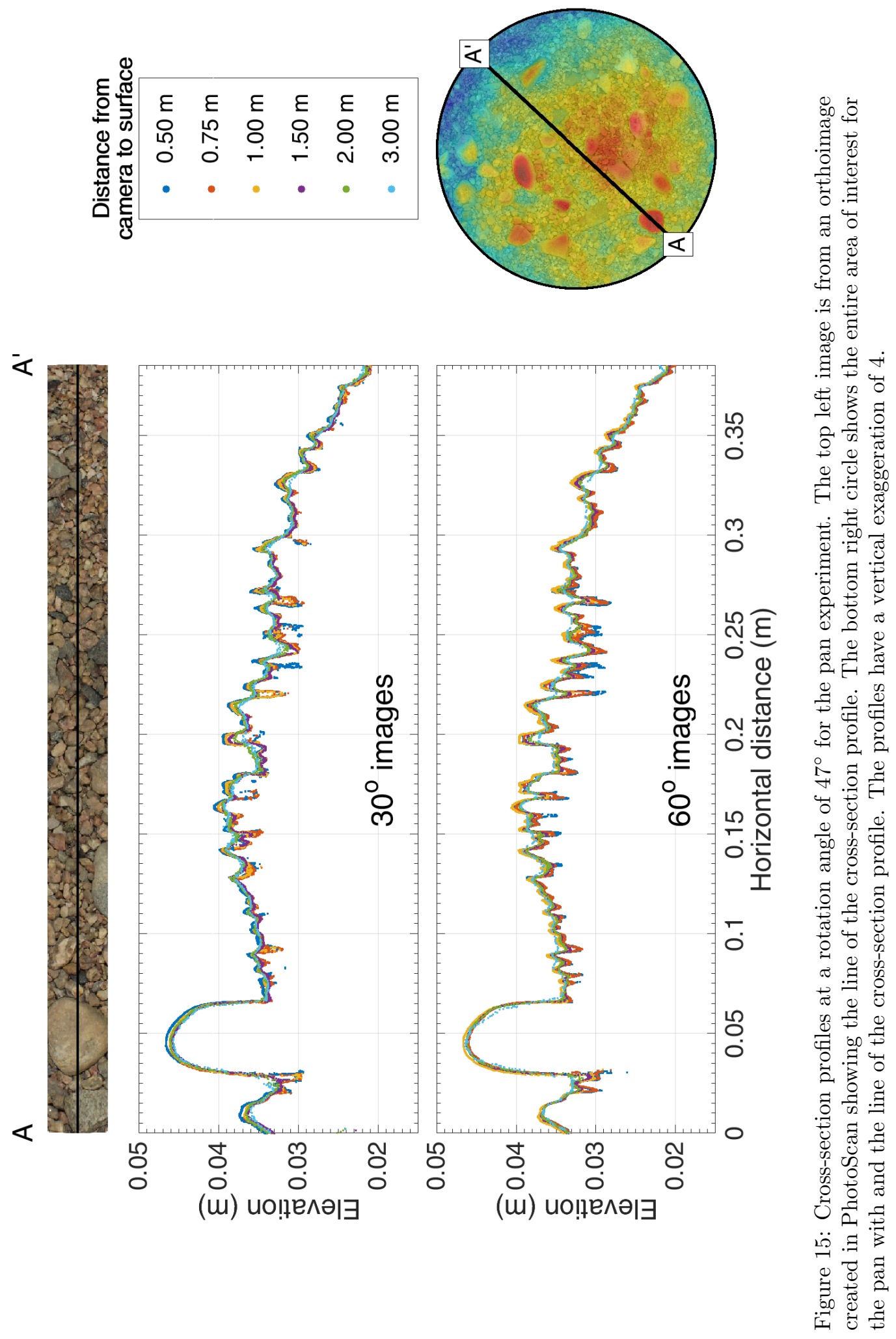




\section{Flume 1}

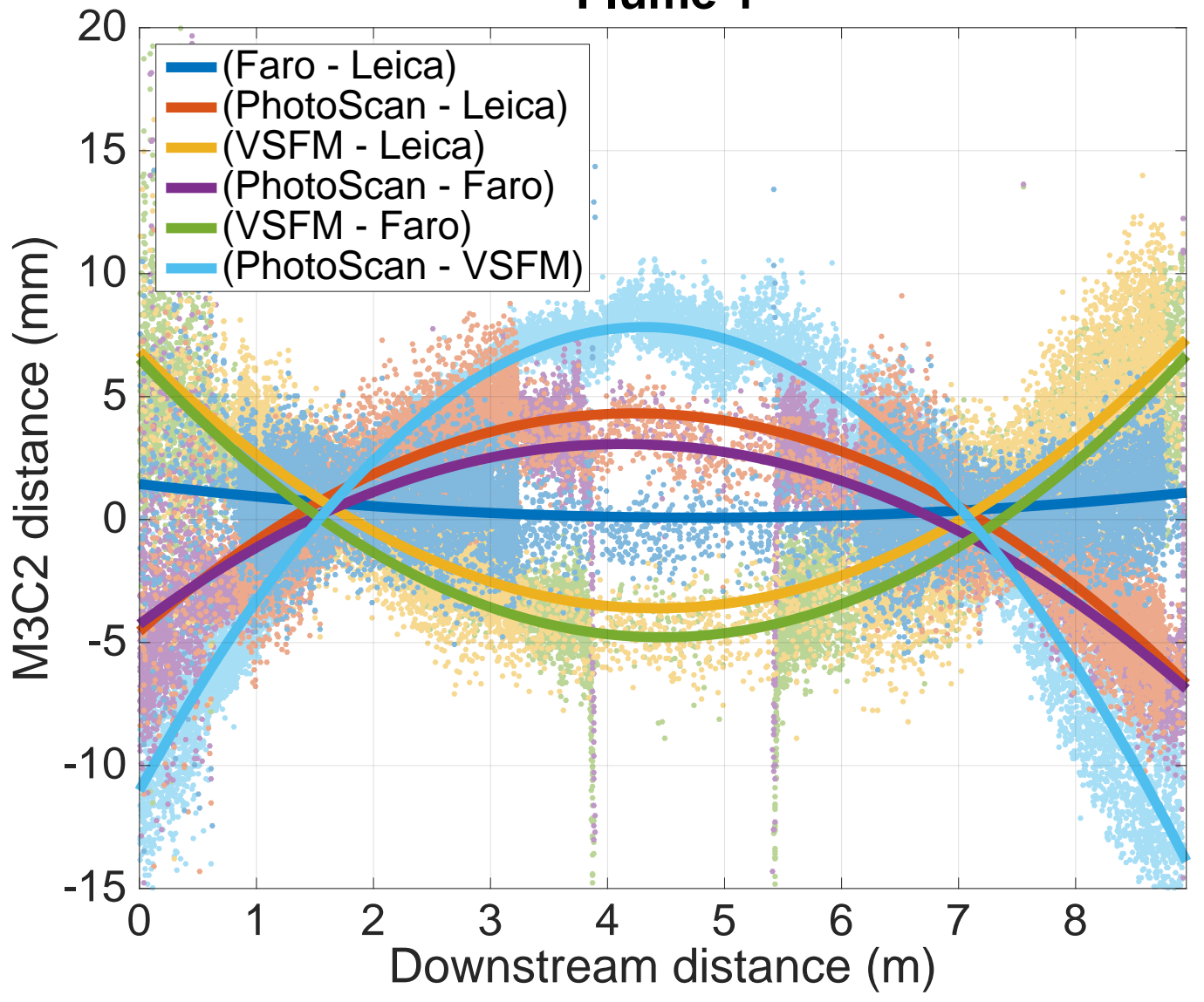

Figure 16: Longitudinal M3C2 differences and fitted second-degree polynomials showing nonlinear deformation in the downstream direction of SfM point clouds for Flume 1. 